Article

\title{
Mapping CORINE Land Cover from Sentinel-1A SAR and SRTM Digital Elevation Model Data using Random Forests
}

\author{
Heiko Balzter ${ }^{1,2, *}$, Beth Cole ${ }^{1, \dagger}$, Christian Thiel ${ }^{3, \dagger}$ and Christiane Schmullius ${ }^{3, \dagger}$ \\ 1 Centre for Landscape and Climate Research, Department of Geography, University of Leicester, \\ University Road, Leicester LE1 7RH, UK; E-Mail: bc132@le.ac.uk \\ 2 National Centre for Earth Observation, University of Leicester, University Road, \\ Leicester LE1 7RH, UK \\ 3 Abteilung Fernerkundung, Institut für Geographie, Friedrich-Schiller-University, Grietgasse 6, \\ D-07743 Jena, Germany; E-Mails: christian.thiel@uni-jena.de (C.T.); \\ c.schmullius@uni-jena.de (C.S.) \\ $\dagger$ These authors contributed equally to this work. \\ * Author to whom correspondence should be addressed; E-Mail: hb91@le.ac.uk; \\ Tel.: +44-116-252-3820.
}

External Editors: Ioannis Gitas and Prasad S. Thenkabail

Received: 13 May 2015 / Accepted: 3 November 2015 / Published: 6 November 2015

\begin{abstract}
The European CORINE land cover mapping scheme is a standardized classification system with 44 land cover and land use classes. It is used by the European Environment Agency to report large-scale land cover change with a minimum mapping unit of 5 ha every six years and operationally mapped by its member states. The most commonly applied method to map CORINE land cover change is by visual interpretation of optical/near-infrared satellite imagery. The Sentinel-1A satellite carries a C-band Synthetic Aperture Radar (SAR) and was launched in 2014 by the European Space Agency as the first operational Copernicus mission. This study is the first investigation of Sentinel-1A for CORINE land cover mapping. Two of the first Sentinel-1A images acquired during its ramp-up phase in May and December 2014 over Thuringia in Germany are analysed. 27 hybrid level 2/3 CORINE classes are defined. 17 of these were present at the study site and classified based on a stratified random sample of training pixels from the polygon-eroded CORINE 2006 map. Sentinel-1A logarithmic radar backscatter at HH and HV polarisation (May acquisition), VV and VH polarisation (December acquisition), and the $\mathrm{HH}$ image texture are used as input bands to the classification. In addition, a Digital Terrain Model
\end{abstract}


(DTM), a Canopy Height Model (CHM) and slope and aspect maps from the Shuttle Radar Topography Mission (SRTM) are used as input bands to account for geomorphological features of the landscape. In future, elevation data will be delivered for areas with sufficiently high coherence from the Sentinel-1A Interferometric Wide-Swath Mode itself. When augmented by elevation data from radar interferometry, Sentinel-1A is able to discriminate several CORINE land cover classes, making it useful for monitoring of cloud-covered regions. A bistatic Sentinel-1 Convoy mission would enable single-pass interferometric acquisitions without temporal decorrelation.

Keywords: SAR; Copernicus; CORINE; land cover; land use; habitat mapping; Shuttle Radar Topography Mission (SRTM); geomorphometry

\section{Introduction}

CORINE land cover mapping provides the only consistent classification system of long-term land cover data in Europe [1]. With its 44 classes, some of which are defined as mixed land cover and land use classes, CORINE provides a European scale map with 25 ha minimum mapping unit for land cover and 5 ha for land cover change every 6 years [2].

CORINE land cover maps are important as a source of operational land cover information for many sectors of the European economy, including risk management for the insurance industry [3], telecommunications planning, environmental reporting, land use impact assessment on the natural environment [4], life cycle analysis [5], biodiversity and habitat conservation [6], population distribution mapping [7], crop forecasting [8], urban heat island studies [9] and others.

Historically, member states of the European Environment Agency have adopted national approaches for the production of CORINE; with many choosing to follow the Agency's published Technical Guidelines [10]. These guidelines foresee a manual digitization of land cover change based on visual interpretation of optical/near-infrared satellite images. This process is both subjective to some extent, even with the internal and external quality assurance and verification steps that are compulsory, and labour intensive. In the current CORINE mapping process to produce a 2012 map, frequent cloud cover has made the provision of optical imagery over the British Isles and parts of Scandinavia very patchy and difficult to fulfil within the specified user requirements.

SAR is an active imaging technique that is not hampered by frequent cloud-cover because microwave radiation penetrates through clouds. The European Space Agency (ESA) has launched the first of its Copernicus Sentinel missions in April 2014. Sentinel-1A provides C-band SAR data in four acquisition modes with a temporal revisit time of 12 days with the first satellite and 6 days once Sentinel-1B has been launched in 2016 [11]. The acquisition modes are Stripmap (SM), Interferometric Wide-Swath (IW), Extra Wide Swath (EW) and Wave Mode (WV). The SM, IW, and EW modes acquire data at a single transmit polarisation ( $\mathrm{H}$ or $\mathrm{V}$ ) and dual receive polarisation ( $\mathrm{HV}$ or $\mathrm{VH})$. The WV mode only has a single polarisation (HH or VV). The default mode over land is the Interferometric Wide-Swath Mode, which provides a $250 \mathrm{~km}$ swath composed of three sub-swaths at 5 $\mathrm{m}$ by $20 \mathrm{~m}$ spatial resolution in single look. It uses a new type of ScanSAR mode called Terrain 
Observation with Progressive Scan (TOPS) SAR, which is shrinking the azimuth antenna pattern along track direction.

Several studies have investigated the suitability of SAR for land cover mapping, but few have aimed at the delineation of a large number of classes, and fewer still have analysed C-band SAR data [12]. Microwave radiation responds to fundamental scattering processes that are determined by surface roughness, soil moisture, vegetation water content and 3D structure of the scattering elements. A C-band SAR-based land cover classification of Kuwait showed a total of 13 classes could be distinguished from ERS-1/2 and Radarsat images [13]. Vegetation cover, surface roughness, percentage of coarse material in the surface layer and moisture conditions influenced the backscatter. Most SAR classification algorithms use fixed polarimetric indices to detect certain land cover types, despite the large natural variability between observation sites, temporal acquisition, environmental conditions and calibration effects. To improve on previous approaches, a decision-tree-based adaptive land cover classification technique has been developed [14].

The potential of Sentinel-1 for land cover mapping [15] was recognised in a study that simulated the planned short revisit and dual-polarization concept of Sentinel-1 with multi-temporal ERS-2 and ENVISAT ASAR AP C-band backscatter data [16]. Five basic level 2 land cover classes could be mapped consistently and operationally with accuracies greater than $85 \%$ covering $75,000 \mathrm{~km}^{2}$ of Belgium, the Netherlands and Germany [16]. C-band SAR backscatter is able to map burnt peat land as was shown for the CORINE peat bog class [17]. Multitemporal/multi-polarization ENVISAT ASAR C-band data were investigated for principal component analysis and classification of five land cover classes in Korea [18]. Sentinel-1 will provide IW mode acquisitions over land areas, making it suitable for SAR interferometry (InSAR), which offers the retrieval of canopy height models and digital terrain models from SAR and is particularly promising for forest mapping [19]. Interferometric coherence also discriminates between forest growing stock volume classes [20].

Some studies cast doubts on the ability of SAR to map land cover with acceptable accuracy. ALOS PALSAR L-band and RADARSAT-2 C-band data were tested for land cover classification in a moist tropical region [21]. L-band provided $72.2 \%$ classification accuracy for a coarse land cover classification system (forest, succession, agro-pasture, water, wetland, and urban) and C-band only $54.7 \%$.

An important feature of SAR images is their image texture, which can be quantified by a range of different statistical measures that are calculated over a moving window of specific size. For example, ALOS PALSAR 50 m FBD data were used to map land cover in Riau province, Sumatra, Indonesia [22]. The radiometric information in the L-band $\mathrm{HH}$ and $\mathrm{HV}$ channels alone was a poor classifier, and textural parameters were needed to achieve land cover class discrimination. The SVM classifier in that study showed an agreement over 70\% with six land cover classes derived from Landsat [22]. Very high resolution TerraSAR-X data were used for land cover mapping by specifying the speckle characteristics of the land cover classes: water; open land (farmland, grassland, bare soil); woodland; and urban area, showing overall accuracies of 77\%-86\% [23]. A combination of radiometric image bands and texture bands also increased the classification accuracies [21].

The multi-temporal capabilities of Sentinel-1 are likely to improve its classification accuracy for land cover applications. Riedel et al. [24] generated a land use map with 20 crop types of Northern Thuringia with $80.2 \%$ overall accuracy from ASAR time-series by including texture information which they 
retrieved from multi-temporal statistics. Another study used X-band SAR with eleven COSMO-SkyMed $\mathrm{HH}$ and HV images for land cover mapping over an agricultural area in Southern Australia [25]. The temporal information improved the classification results, with an overall accuracy of ca. $82 \%$ for 10 classes [25]. Five land use/land cover types (forests, urban infrastructure, surface water and marsh wetland) were mapped from multi-temporal polarimetric RADARSAT-2 imagery in North-eastern Ontario, Canada [26]. Wetlands showed a seasonal increase in HH and HV backscatter intensity due to the growth of emergent vegetation over the summer but other classes showed little temporal variation in backscatter. Multi-temporal RADARSAT-2 polarimetric SAR data were used to discriminate highdensity residential areas, low-density residential areas, industrial and commercial areas, construction sites, parks, golf courses, forests, pasture, water, and two types of agricultural crops using an objectbased support vector machine and a rule-based approach $(\kappa=0.91)$ [27]. In the Brazilian Pantanal, multitemporal L-band ALOS/PALSAR and C-band RADARSAT- 2 data gave an accuracy of $81 \%$ for the land cover types of forest, savanna, grasslands/agriculture, aquatic vegetation and open water [28].

Knowledge-based models have been used to determine hierarchical decision rules to differentiate land cover classes [29]. In the approach by Dobson et al. [29] the classifier produces two levels of classification, first a terrain differentiation into man-made features (urban), surfaces, short vegetation, and tall vegetation, followed by a level 2 differentiation of the tall vegetation class based on foliage and growth form of woody stems (excurrent, decurrent, and columnar tree architecture), leading to overall accuracies over $90 \%$ in northern Michigan. The knowledge-based SAR-based classification by Dobson et al. [29] was superior to unsupervised classification of multi-temporal AVHRR data. A dictionary- and rule-based model selection approach was developed in an adaptive contextual semi-supervised algorithm for multi-temporal RADARSAT-2 polarimetric SAR (PolSAR) data [30]. The best overall classification accuracy it achieved was $89.99 \%$.

The synergistic use of optical and SAR data improves classification accuracy. Five land cover classes in the Arctic tundra were mapped with dual-polarized TerraSAR-X (HH/VV), quad-polarized Radarsat-2 and Landsat 8 imagery [31]. The overall accuracy increased if both SAR and optical data were used (71\% unsupervised Landsat 8 and TerraSAR-X; 87\% supervised Landsat 8 and Radarsat-2).

Hierarchical decision trees are appealing for land cover mapping but usually require an interpretation by the observer to set the branching rules. To avoid reliance on this a priori knowledge, ensemble classification methods that originate from machine learning are increasingly prominent in the recent literature. One such method is random forests, a machine learning supervised classifier developed by Breiman [32]. Random forests often provide better land cover classification accuracies than for example the maximum likelihood approach [33]. In Waske and Brown [33], boosted decision trees and random forests were applied to multi-temporal C-band SAR data from different study sites and years. Random forests outperformed all other classifiers and reached nearly $84 \%$ overall accuracy in rural areas [33]. Random forest classification has been applied to salt marsh vegetation mapping from quad-polarimetric airborne S- and X-band SAR, elevation and optical data [34].

This comprehensive literature review shows that most studies have limited themselves to mapping around five land cover classes from SAR, with only a handful of studies expanding the classification scheme to include more classes. Besides, no published studies of real Sentinel-1 data for the mapping of land cover classes are in the public domain at the date this manuscript was written. 
This paper examines what is achievable from summer and winter acquisitions of Sentinel-1A dual-polarisation SAR data aided by prior knowledge of past land cover and digital elevation data from the Shuttle Radar Topography Mission.

\section{Materials and Methods}

The present study analyses two of the first Sentinel-1A SAR image acquisitions over Thuringia, Germany. The first, uncalibrated Sentinel-1A image was acquired during the ramp-up phase on 2 May 2014 (Scene ID = S1A_IW_GRDH_1SDH_20140502T170314_20140502T170343_000421_0004CC), in ascending orbit at $\mathrm{HH}$ and $\mathrm{HV}$ polarisations. The second image was acquired on 9 December 2014 (Scene ID = S1A_IW_GRDH_1SDV_20141209T053327_20141209T053352_003638_0044F6), in descending orbit at $\mathrm{VV}$ and $\mathrm{VH}$ polarisations. Both images were processed to the Standard Level 1 Product, GRDH (ground-range detected, high resolution) by ESA. The images were not fully calibrated because during the Sentinel-1A ramp-up phase the calibration constants were not yet available from ESA, meaning that the backscatter values are not on an absolute scale. The backscatter bands contain Digital Numbers which are converted to the $\mathrm{dB}$ scale. The image bands are resampled to $100 \mathrm{~m}$ spatial resolution using bilinear interpolation. Texture bands are calculated from the GRDH image products within a moving 5 by 5 pixel window, calculating the variance within each window and them resampling to $100 \mathrm{~m}$ spatial resolution.

SRTM data [35-38] at $100 \mathrm{~m}$ spatial resolution were obtained from opentopography.org and SLOPE and ASPECT are calculated from the DTM in order to take into account the prevalence of certain land cover types on specific slopes, aspects or altitudes.

The 2006 CORINE land cover map for Germany was produced using the standard method of visual interpretation based upon the EEA technical guidelines [10] and obtained as a gridded $100 \mathrm{~m}$ resolution product. A hybrid CORINE level 2/level 3 classification scheme of 27 classes is devised (Table 1), based on knowledge of the scattering mechanisms of C-band SAR and the dependence of certain land cover types on geomorphology. All spatial data are resampled to the $100 \mathrm{~m}$ grid with a Lambert Azimuthal Equal Area projection (latitude at projection centre $=52^{\circ}$, longitude at projection centre $=10^{\circ}$, false easting $=4,321,000 \mathrm{~m}$, false northing $=3,210,000 \mathrm{~m}$, GRS80 ellipsoid, units $=$ metre). The hybrid CORINE land cover map 2006 is used for the automatic extraction of pixels as training sites for the classifiers. To minimise edge effects, its polygons were first eroded by 5 pixels along the edges. Polygon erosion results were performed with different numbers of pixels $(3,5$ and 7$)$ and 5 pixels lead to eroded polygon areas that are sufficiently free of edge effects and location uncertainty effects from overlaying the CORINE polygon boundaries and the SAR viewing geometry. Up to 20,000 stratified random samples of training pixels are chosen for each CORINE class. A stratified random sampling approach is statistically appropriate for sampling distributions with highly imbalanced sample sizes such as often found in land cover datasets. We explored different caps of the number of training pixels and found that 20,000 was a good compromise between computational efficiency (because larger numbers increase the RF computation time) and coverage of representative areas of land cover types (which can be an issue if too few samples are used from land cover types with large area extent that become under-sampled and hence biased). 
The processing of all datasets was implemented in R [39], using the R packages "randomForest" [40], “sp" [41,42], "caTools", "gdalUtils", "rgdal”, "foreign", "raster", "fields", "rasclass" and "mmand". Four random forest (RF) classifications are performed with different input bands to assess their relative performance:

(i) RFPOL classification: A purely radiometric classification with $\mathrm{HH}$ and $\mathrm{HV}$ polarisations from May 2014 and VV and VH from December 2014.

(ii) RFTEX classification: Radiometric and texture information, with $\mathrm{HH}$ and $\mathrm{HV}$ polarisations from May 2014 and VV and VH from December 2014, as well as the HH texture band.

(iii) RFTEXSRTM classification: An integrated radiometric and texture classification with auxiliary geomorphometric input bands, using HH and HV polarisations from May 2014 and VV and VH from December 2014, the HH texture band, and the Digital Terrain Model (DTM), Canopy Height Model (CHM) and SLOPE and ASPECT maps from the Shuttle Radar Topography Mission (SRTM).

(iv) RFSRTM classification: A pure terrain classification using only the Digital Terrain Model (DTM), Canopy Height Model (CHM) and SLOPE and ASPECT maps from the Shuttle Radar Topography Mission (SRTM).

The principle of a random forest is the classification of the image layers by constructing a large number of decision trees [32]. Random forests train classifiers to generate class predictions for unseen data. Randomness is introduced by bootstrapping and random selection of a subset of $m$ variables to split at each node of a tree. Splitting thresholds are defined using the Gini Index, which is a measure of the child node class homogeneity with respect to the distribution of classes in the parent node. Each object (either a pixel or a polygon) is classified as the class which gets the most "votes" from all the decision trees in the random forest. In the original implementation trees are grown to the largest possible size without pruning [32].

Each of the RF classifiers used here generated 201 decision trees. All classifiers are post-processed with a 3 by 3 pixel local mode filter to remove isolated pixels and reduce noise in the land cover maps. The accuracy of the classified maps is assessed by calculating the out-of-bag error rates of the random forests for each CORINE class over the training pixels. The out-of-bag error rate is estimated internally by the random forest during the construction of each tree from a different bootstrap sample from the original data. One-third of the pixels (cases) are left out of the bootstrap sample for each tree and are then classified with that tree. A test classification of each pixel is obtained in this way from one-third of all trees. These independent test sets are used to estimate the out-of-bag error rate. It provides an unbiased estimate of the true map accuracy [32].

Random forests allow the analysis of the variable importance with the Gini coefficient, which is a measure of the homogeneity of a distribution, ranging from 0 (completely homogeneous) to 1 (completely heterogeneous). The Gini coefficient originates from Economics where it is used to describe the inequalities of the distribution of wealth. In random forests, the Gini coefficient is calculated each time a particular input variable is used to split a node. The Gini coefficient for the child nodes are compared to that of the original node. If the split improves the homogeneity of classes, the Gini coefficient will decrease after splitting the node. All decreases in the Gini coefficient that are achieved for the nodes are added up for each input variable. Hence, input variables that result in nodes with higher classification purity have a higher decrease in Gini coefficient overall. 
Table 1. Description of the CORINE level 3 classification scheme with the original level 3 codes and the hybrid CORINE level $2 / 3$ scheme used in this study with recoded class codes.

\begin{tabular}{|c|c|c|c|}
\hline Code & CORINE Level 3 & Recoded & Hybrid CORINE Level 2/3 \\
\hline 111 & Continuous urban fabric & 111 & Continuous urban fabric \\
\hline 112 & Discontinuous urban fabric & 112 & Discontinuous urban fabric \\
\hline 121 & Industrial or commercial units & \multirow{4}{*}{120} & \multirow{4}{*}{$\begin{array}{l}\text { Industrial, commercial and } \\
\text { transport units }\end{array}$} \\
\hline 122 & Road and rail networks and associated land & & \\
\hline 123 & Port areas & & \\
\hline 124 & Airports & & \\
\hline 131 & Mineral extraction sites & \multirow{3}{*}{130} & \multirow{3}{*}{$\begin{array}{l}\text { Mine, dump and construction } \\
\text { sites }\end{array}$} \\
\hline 132 & Dump sites & & \\
\hline 133 & Construction sites & & \\
\hline 141 & Green urban areas & \multirow{2}{*}{140} & Artificial, non-agricultural \\
\hline 142 & Sport and leisure facilities & & vegetated areas \\
\hline 211 & Non-irrigated arable land & 211 & Non-irrigated arable land \\
\hline 212 & Permanently irrigated land & 212 & Permanently irrigated land \\
\hline 213 & Rice fields & 213 & Rice fields \\
\hline 221 & Vineyards & \multirow{3}{*}{220} & \multirow{3}{*}{ Permanent crops } \\
\hline 222 & Fruit trees and berry plantations & & \\
\hline 223 & Olive groves & & \\
\hline 231 & Pastures & 230 & Pastures \\
\hline 241 & Annual crops associated with permanent crops & \multirow{4}{*}{240} & \multirow{4}{*}{ Heterogeneous agricultural areas } \\
\hline 242 & Complex cultivation patterns & & \\
\hline 243 & $\begin{array}{l}\text { Land principally occupied by agriculture, with } \\
\text { significant areas of natural vegetation }\end{array}$ & & \\
\hline 244 & Agro-forestry areas & & \\
\hline 311 & Broad-leaved forest & 311 & Broad-leaved forest \\
\hline 312 & Coniferous forest & 312 & Coniferous forest \\
\hline 313 & Mixed forest & 313 & Mixed forest \\
\hline 321 & Natural grasslands & 321 & Natural grasslands \\
\hline 322 & Moors and heathland & 322 & Moors and heathland \\
\hline 323 & Sclerophyllous vegetation & 323 & Sclerophyllous vegetation \\
\hline 324 & Transitional woodland-shrub & 324 & Transitional woodland-shrub \\
\hline 331 & Beaches, dunes, sands & 331 & Beaches, dunes, sands \\
\hline 332 & Bare rocks & 332 & Bare rocks \\
\hline 333 & Sparsely vegetated areas & 333 & Sparsely vegetated areas \\
\hline 334 & Burnt areas & 334 & Burnt areas \\
\hline 335 & Glaciers and perpetual snow & 335 & Glaciers and perpetual snow \\
\hline 411 & Inland marshes & \multirow{2}{*}{410} & \multirow{2}{*}{ Inland wetlands } \\
\hline 412 & Peat bogs & & \\
\hline 421 & Salt marshes & \multirow{3}{*}{420} & \multirow{3}{*}{ Maritime wetlands } \\
\hline 422 & Salines & & \\
\hline 423 & Intertidal flats & & \\
\hline 511 & Water courses & \multirow{2}{*}{510} & \multirow{2}{*}{ Inland waters } \\
\hline 512 & Water bodies & & \\
\hline 521 & Coastal lagoons & \multirow{3}{*}{520} & \multirow{3}{*}{ Marine waters } \\
\hline 522 & Estuaries & & \\
\hline 523 & Sea and ocean & & \\
\hline
\end{tabular}


Table 2. Number of pixels selected randomly for each hybrid CORINE level 2/3 class as training data for the classifiers.

\begin{tabular}{llcc}
\hline Class & \multicolumn{1}{c}{ Description } & $\begin{array}{c}\text { Number of Pixels in } \\
\text { the CLC 2006 Map }\end{array}$ & $\begin{array}{c}\text { Number of } \\
\text { Training Pixels }\end{array}$ \\
\hline 111 & Continuous urban fabric & 543 & 119 \\
112 & Discontinuous urban fabric & 50,613 & 8,832 \\
120 & Industrial, commercial and transport units & 9,117 & 1,143 \\
130 & Mine, dump and construction sites & 1,641 & 68 \\
140 & Artificial, non-agricultural vegetated areas & 3,574 & 271 \\
211 & Non-irrigated arable land & 431,518 & 20,000 \\
220 & Permanent crops & 1,915 & 395 \\
230 & Pastures & 80,113 & 14,972 \\
240 & Heterogeneous agricultural areas & 38,663 & 6,549 \\
311 & Broad-leaved forest & 102,895 & 20,000 \\
312 & Coniferous forest & 202,476 & 20,000 \\
313 & Mixed forest & 58,720 & 13,473 \\
321 & Natural grasslands & 11,356 & 5,145 \\
322 & Moors and heathland & 247 & 12 \\
324 & Transitional woodland-shrub & 1,431 & 132 \\
410 & Inland wetlands & 395 & 32 \\
510 & Inland waters & 2,748 & 334 \\
\hline
\end{tabular}

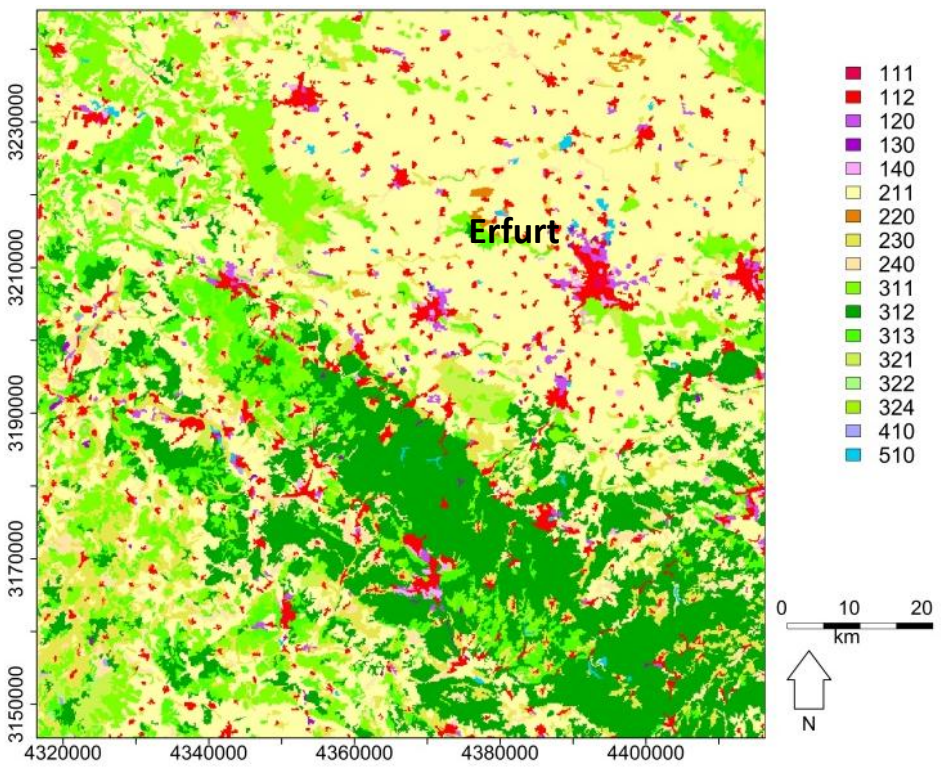

(a)

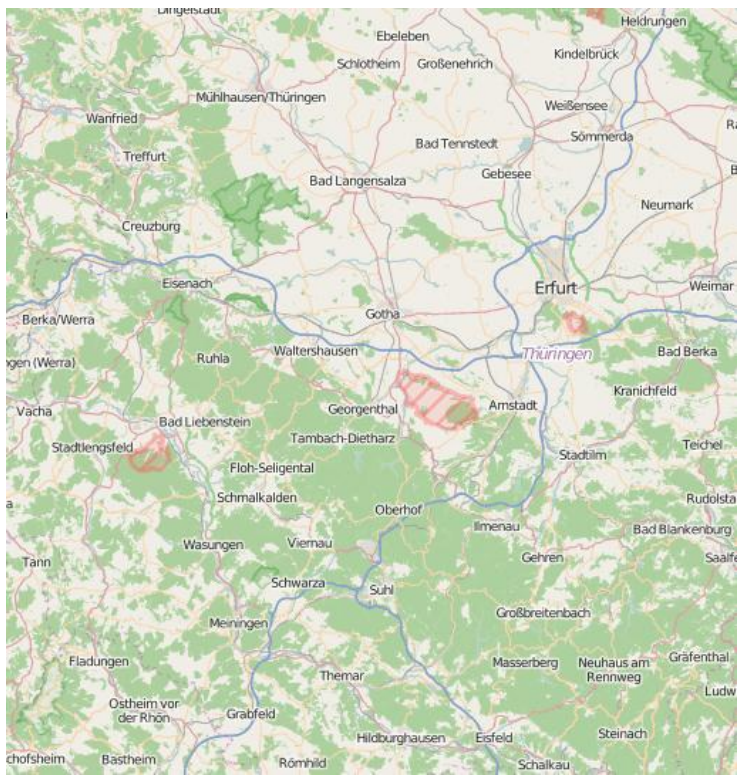

(b)

Figure 1. Maps of the study area in Thuringia, Germany, showing the city of Erfurt. (a) CORINE Land Cover Map 2006. See Table 1 for class definitions. (b) Street map (c) OpenStreetMap contributors.

Table 2 shows the number of training pixels for each CORINE class, it follows the distribution of dominant classes of the overall CORINE map. The number of training pixels per class was capped at a maximum of 20,000 but some classes had fewer pixels in the polygon eroded CORINE image band. Bare rocks were masked out from the analysis due to their small sample size. 
The hybrid CORINE land cover map for the study area and an OpenStreetMap quicklook are shown in Figure 1. The study area is a homogeneous landscape covered by a large expanse of non-irrigated agricultural land (211), punctuated by permanent crops (220), mainly vineyards and fruit trees, pastures (230) consisting of small linear features on more marginal land often following landscape features such as rivers and the transport network, broadleaf (311), coniferous (312) and mixed forests (313) on the steeper and higher ground and discontinuous urban fabric (112) in the towns and villages.

The largest city appearing in red is Erfurt (Figure 1). The elevation of the study region varies from $86 \mathrm{~m}$ to $973 \mathrm{~m}$ (mean $=388 \mathrm{~m}$ ). After polygon erosion and training pixel selection, the signatures of the hybrid CORINE classes were calculated from the training pixels.

\section{Results}

\subsection{Sentinel-1A Radiometric Signatures and Information Content of the Texture and SRTM Bands}

The radiometric signatures of the Sentinel-1A C-band backscatter bands at all polarisations from both dates and the $\mathrm{HH}$ texture band are shown in the boxplots in Figure 2 to illustrate the information content of the different bands for each land cover class. For example, classes 111 (continuous urban fabric), 112 (discontinuous urban fabric) and 120 (industrial, commercial and transport units) have a high $\mathrm{C}-\mathrm{HH}$ backscatter and high $\mathrm{HH}$ texture in comparison to the other classes. Class 140 (artificial, non-agricultural vegetated areas) also has higher texture than the non-artificial surface classes (211-510).

Boxplots of the distribution of the SRTM data bands for each training class are shown in Figure 3. Classes 312 (Coniferous forest), 321 (Natural grasslands) and 322 (Moors and heathland) and to a lesser extent 230 (Pastures), 240 (Heterogeneous agricultural areas), 311 (Broad-leaved forest), 313 (Mixed forest), 324 (Transitional woodland-shrub) and 410 (Inland wetlands) are situated at a higher altitudinal range in the landscape, where soils tend to be less fertile and cooler temperatures are less suitable for intensive agriculture (Figure 3a). Classes 111 (Continuous urban fabric) and 220 (Permanent crops) are constrained to a lower altitudinal range.

Forests $(311,312,313)$ in the study region tend to occur on steep slopes (Figure 3b). Classes 130 (Mine, dump and construction sites), 140 (Artificial, non-agricultural vegetated areas), 230 (Pastures), 240 (Heterogeneous agricultural areas), 311 (Broad-leaved forest), 312 (Coniferous forest), 313 (Mixed forest), 322 (Moors and heathland) and 324 (Transitional woodland-shrub) are predominantly sited on slopes between $2.5^{\circ}$ and $10^{\circ}$ reaching $25^{\circ}$ in the extreme (Figure $3 \mathrm{~b}$ ).

To distinguish forest cover from non-forest, the CHM derived from the SRTM mission is a very good predictor. All forest classes (311 Broad-leaved forest, 312 Coniferous forest, and 313 Mixed forest) and also class 322 (Moors and heathland) show distinctively high canopy height (Figure 3c). The class 324 (Transitional woodland-shrub) has lower CHM values than the mature forest classes 311-313 but taller than agricultural land (211-240) (Figure 3c). This class includes bushy or herbaceous vegetation with scattered trees, representing woodland degradation or forest regeneration areas. The main occurrences of this class include transitional phases between clear-cutting and forest regrowth. Figure $3 \mathrm{~d}$ shows the aspect angles of each land cover class as rose diagrams. 
CHH May

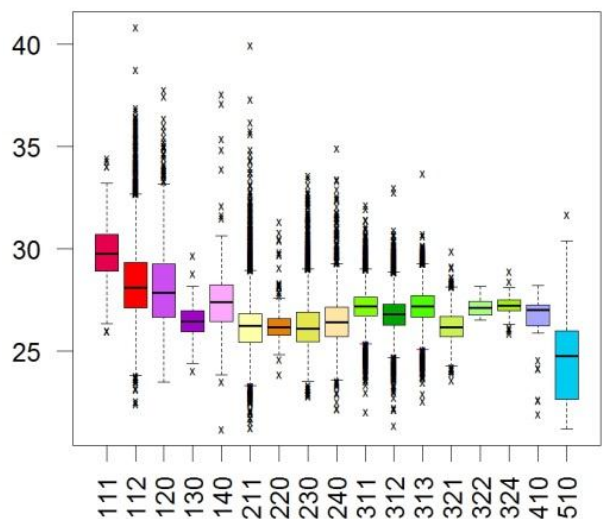

(a)

CVV Dec

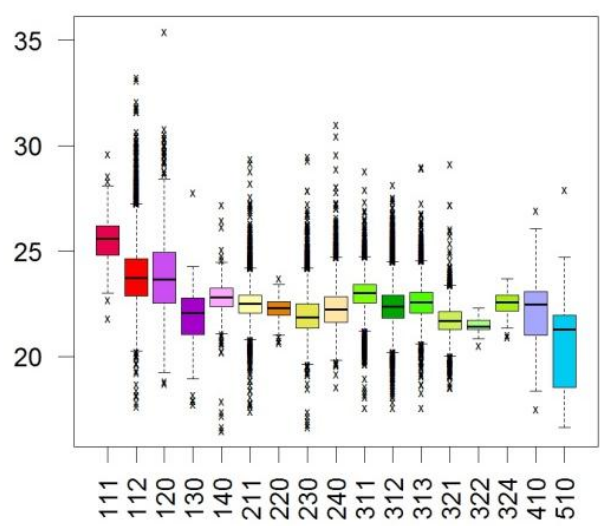

(c)

TEXVARHH

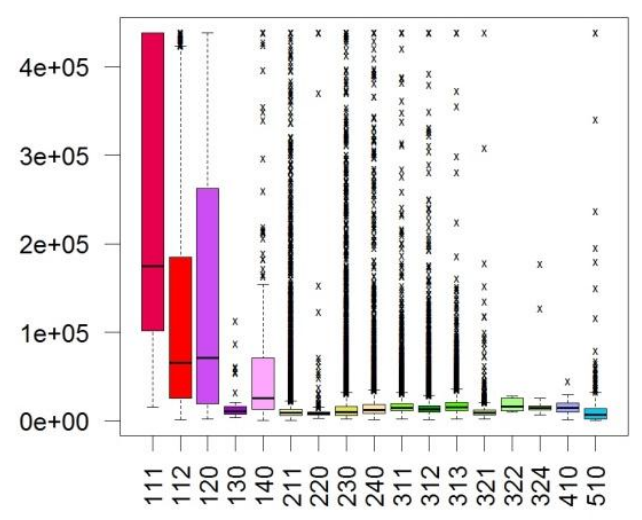

(e)

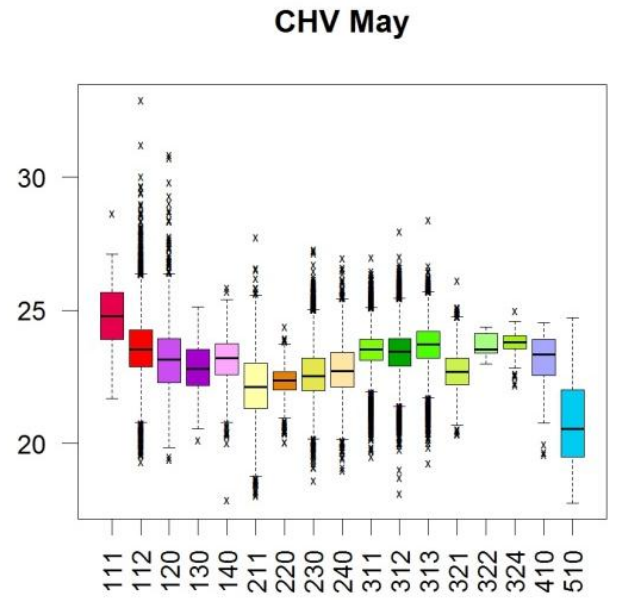

(b)

CVH Dec

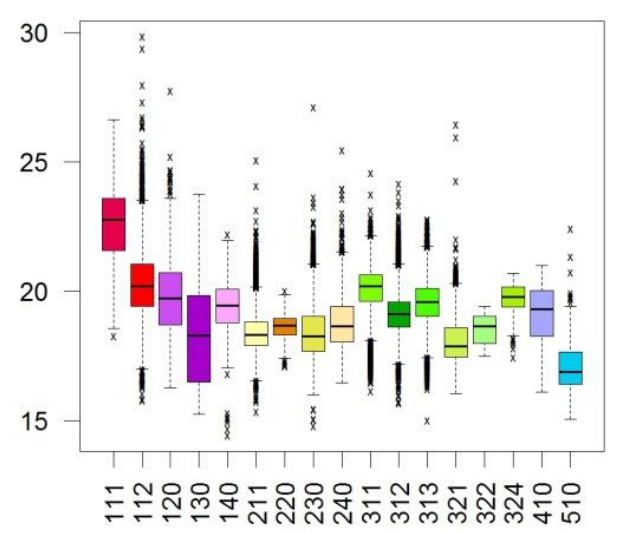

(d) 
DTM

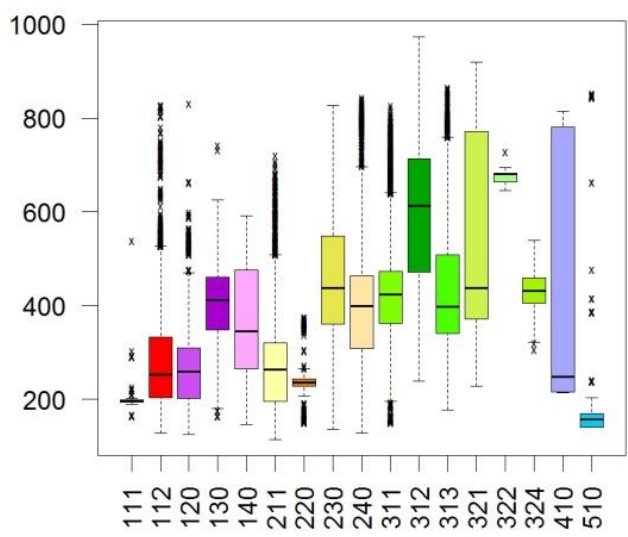

(a)

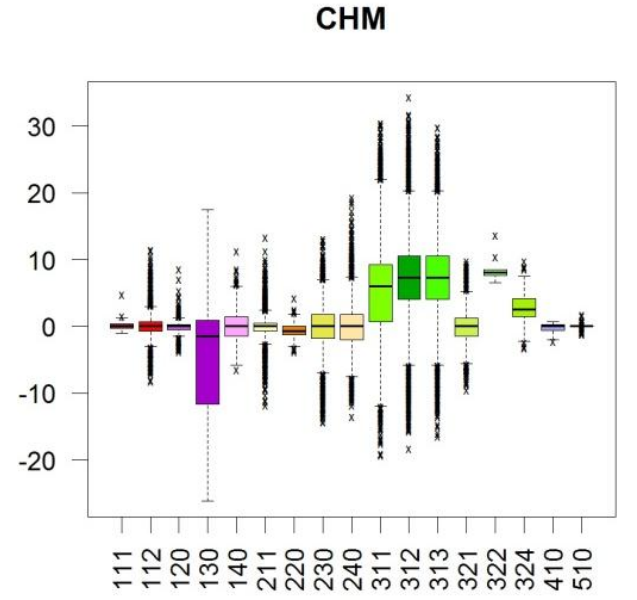

(c)
Slope

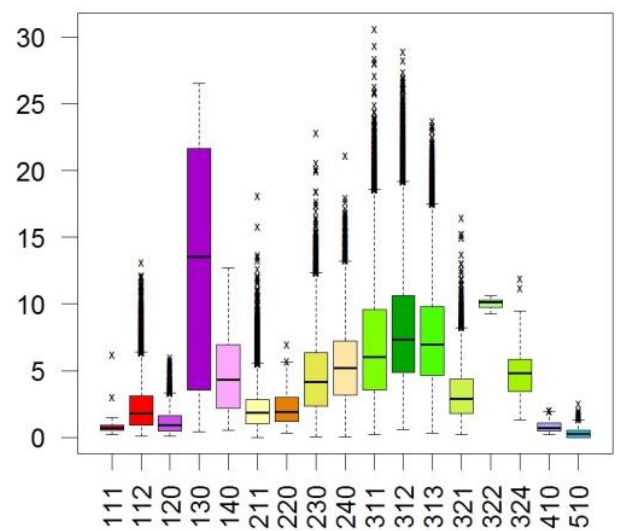

(b)

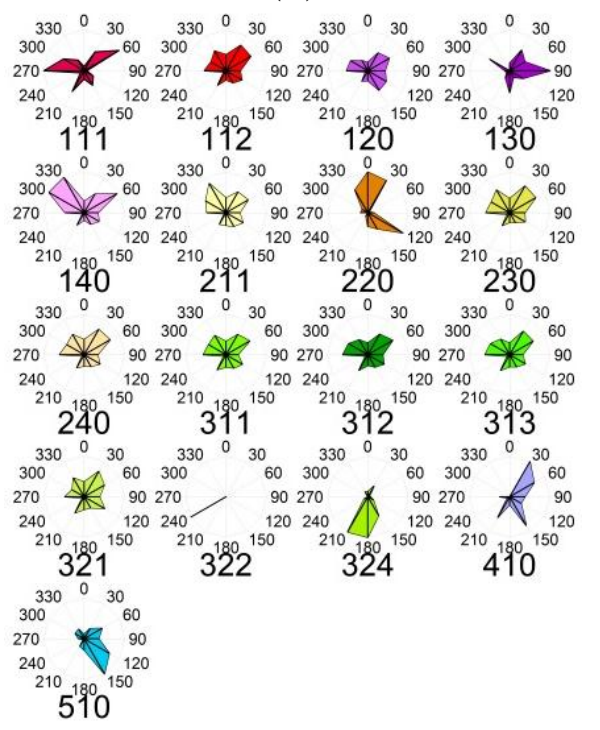

(d)

Figure 3. Boxplots of the Shuttle Radar Topography Mission (SRTM) bands of the randomly chosen training sites for each CORINE class in Table 2 on the $\mathrm{x}$ axis. (a) Digital Terrain Model (DTM). (b) Slope derived from the DTM. (c) Canopy Height Model (CHM). (d) Rose diagrams of the aspect angle by CORINE class.

Figure 4 shows the Sentinel-1A image bands at HH and HV polarisation (acquired in May 2014), the VV and VH polarisation (acquired in December 2014) and the HH image texture band. The HH, $\mathrm{VV}$ and $\mathrm{VH}$ polarisations and $\mathrm{HH}$ texture show urban areas as brighter shades of grey, indicating high backscatter intensity and high texture due to the urban fabric. The HV polarisation clearly shows agricultural fields with crop cover and forests, and the VH image from December 2014 shows the same fields are not covered with crops anymore after harvesting.

In Figure 5 the SRTM data bands (DTM, SLOPE, ASPECT and CHM) are presented. The slopes derived from the DTM also show that the forested higher elevation areas tend to have steeper slopes (Figure 5b). The CHM from the SRTM (Figure 5d) clearly discriminates between the forested and non-forested areas. Classes 311 (Broad-leaved forest), 312 (Coniferous forest), 313 (Mixed forest) and 324 (Transitional woodland-shrub) in Figure 1 all show tall canopies in the CHM boxplots in Figure 3c and show up clearly as high CHM values in Figure 5d. 


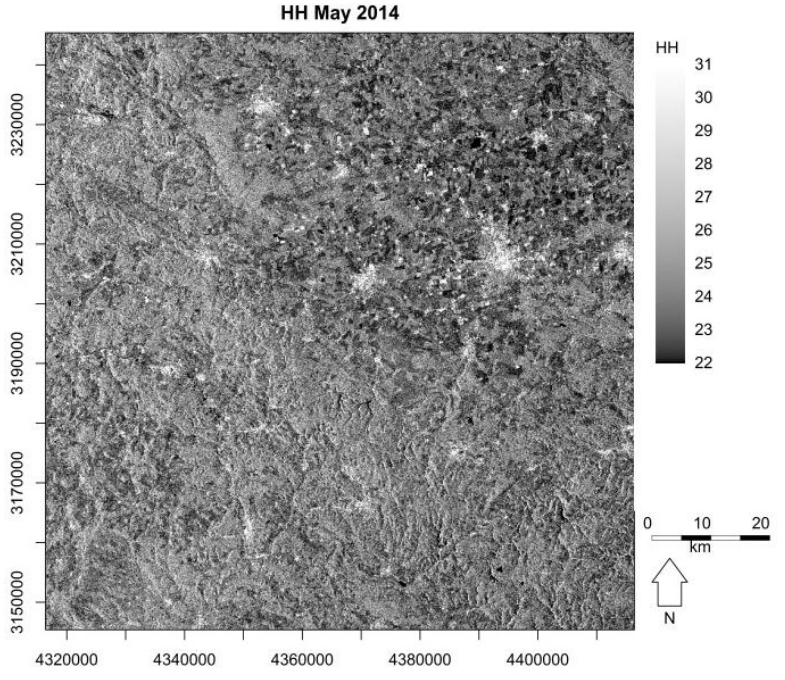

(a)

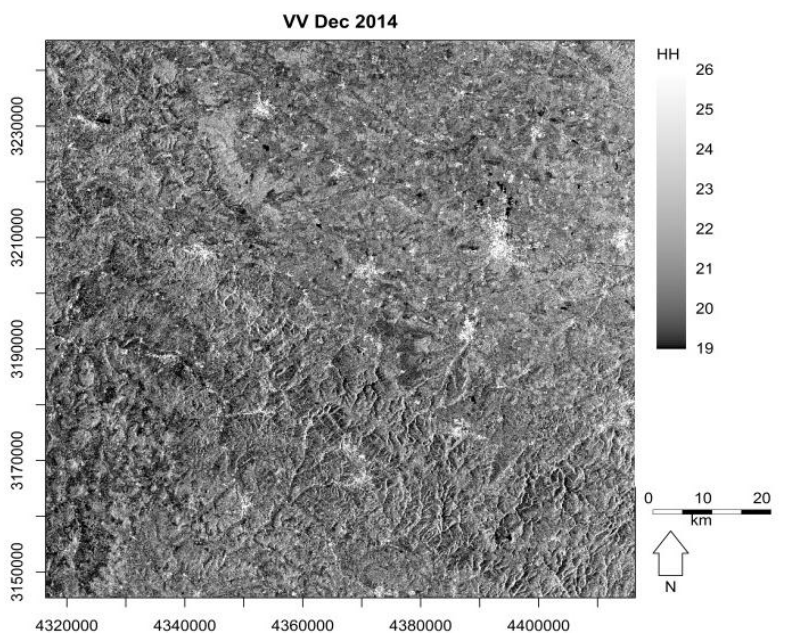

(c)

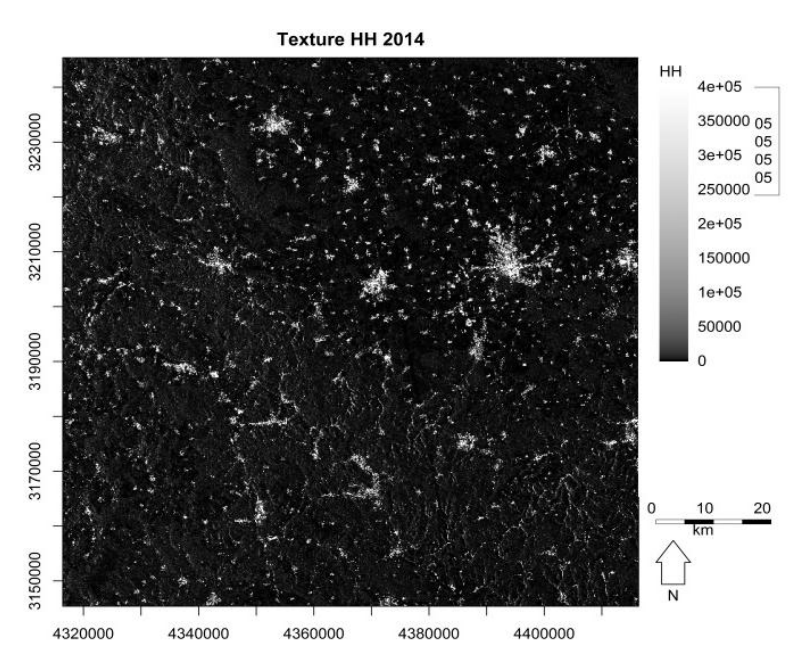

(e)

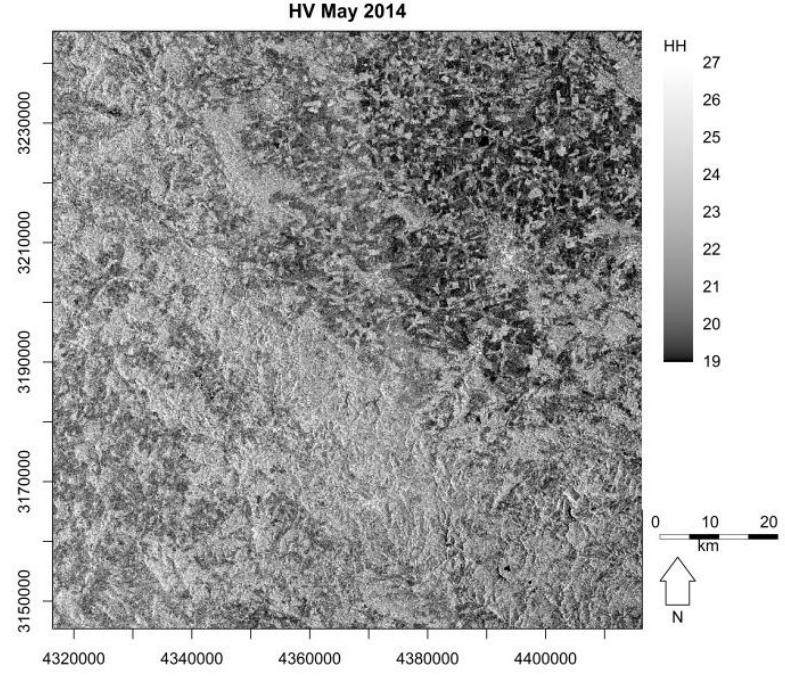

(b)

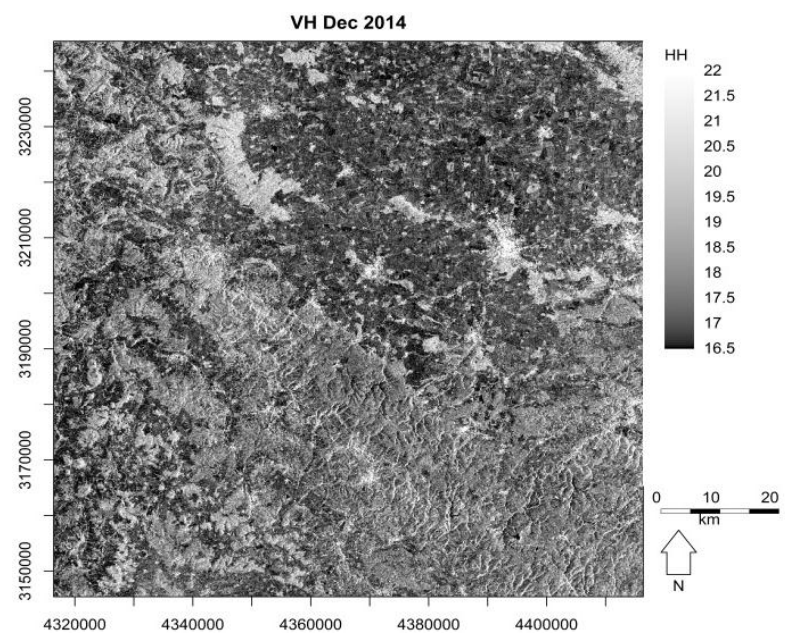

(d)

Figure 4. Sentinel-1A SAR C-band image bands. (a) HH polarisation (May 2014). (b) HV polarisation (May 2014). (c) VV polarisation (December 2014). (d) VH polarisation (December 2014). (e) HH image texture $(5 \times 5$ variance $)$. 


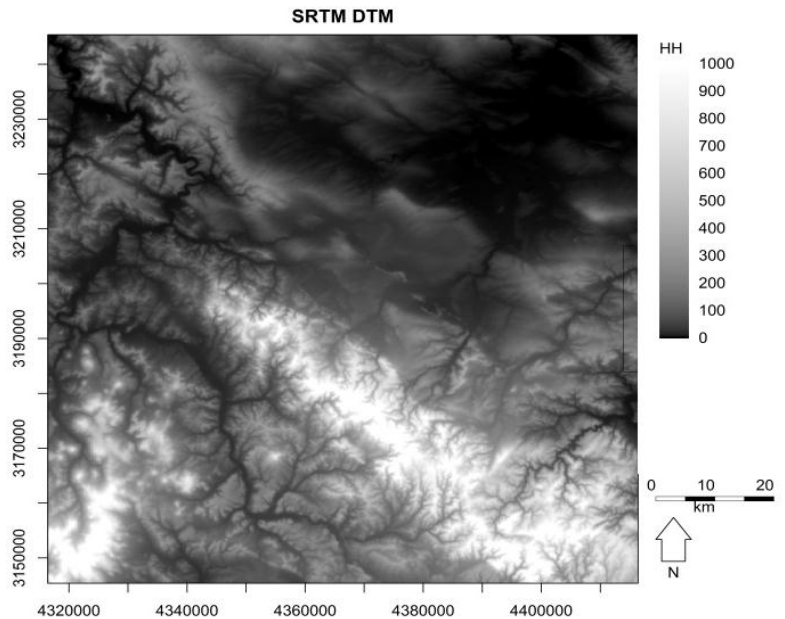

(a)

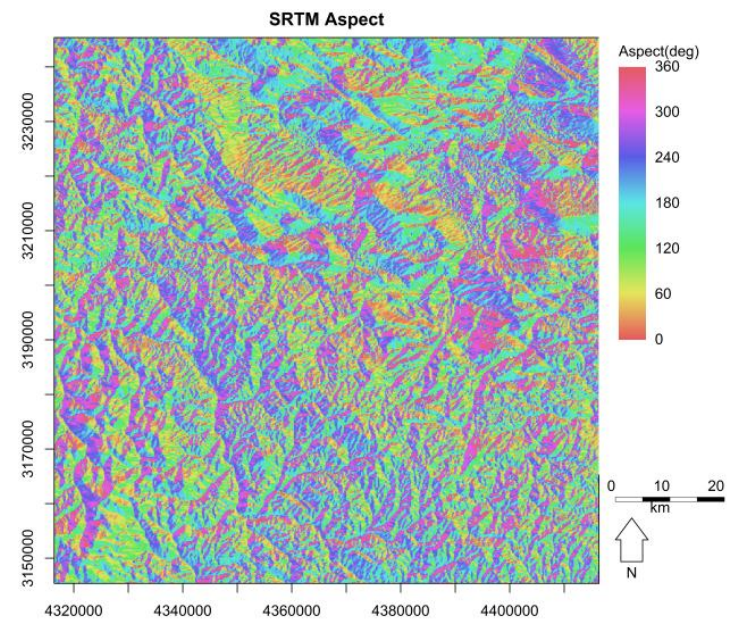

(c)

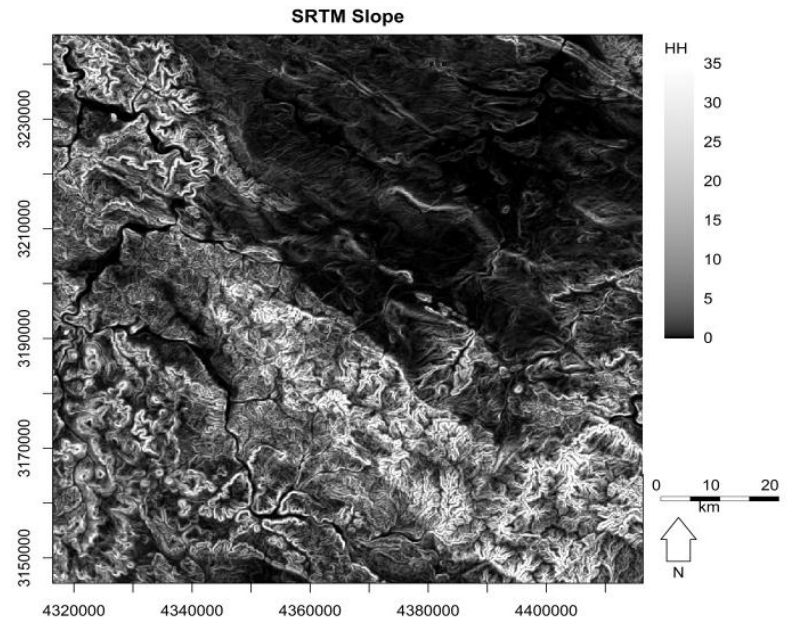

(b)

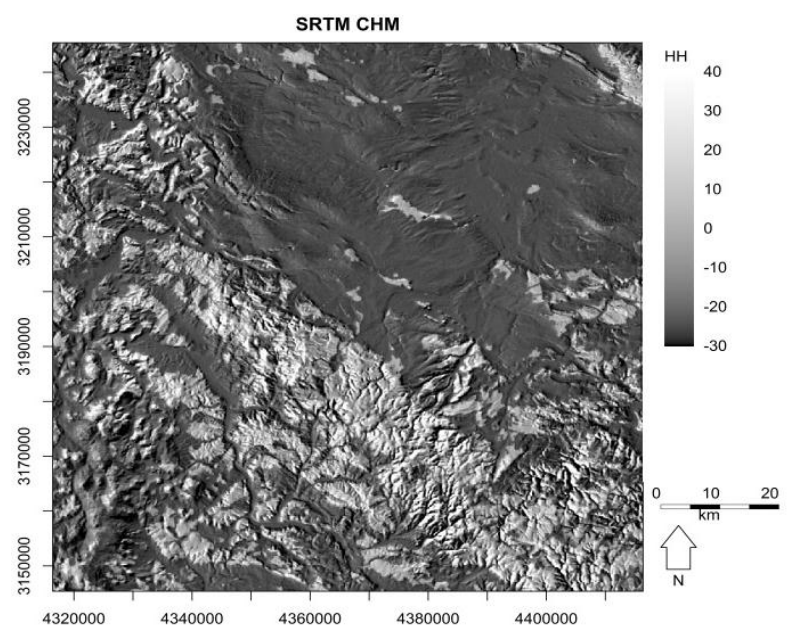

(d)

Figure 5. Shuttle Radar Topography Mission (SRTM) bands of the study area. (a) Digital Terrain Model (DTM). (b) Slope derived from the DTM. (c) Aspect derived from the DTM. (d) Canopy Height Model (CHM).

\subsection{Classification Results}

Figure 6 shows the results from all three classifiers. Each classified map can be compared with the CORINE map in Figure 6e. The RFPOL Random Forest Classification of the radiometric SAR bands in Figure 6a confuses some agricultural crops with forest classes. The Random Forest Classification RFTEX (Figure 6b), which includes the HH texture band, also shows some agricultural areas as forests compared to the CORINE map in Figure 6e.

A quantitative accuracy assessment of all classifiers was carried out by using the out-of-bag error rate, which as discussed above is a good unbiased predictor of the overall classification accuracy. This approach has the advantage that it only uses the pure CORINE pixels after polygon erosion and not any mixed pixels along the edges which could confound the confusion matrix. The RFPOL Random Forest has an out-of-bag error rate of $52.5 \%$ equivalent to an accuracy of $47.5 \%$ and a $\kappa$ coefficient of 0.38 (Table 3). To some extent, land cover change between 2006 and 2014 is likely to have contributed to the high out-of-bag error rate. The CORINE map was last updated in 2006 and the Sentinel-1A 
images were acquired in 2014. However, a large proportion of the error is clearly due to a misclassification. Table 3 shows that many pixels that are agricultural land (211) in the CORINE 2006 map were classified as broad-leaved forest (311) or mixed forest (313).

The RFTEX Random Forest has a similar out-of-bag error rate of $52.5 \%$ and the same $\kappa=0.38$ as RFPOL. Table 4 shows that the amount of confusion of the agricultural class (211) with broad-leaved (311), coniferous (312) or mixed forest (313) is about the same as for RFPOL in Table 3.

After adding the SRTM-derived DTM, CHM, SLOPE and ASPECT as input bands to the Random Forest Classification (RFTEXSRTM), the quality of the classified map is improved substantially with an out-of-bag error rate of $31.6 \%(68.4 \%$ accuracy) and $\kappa=0.63$ (Table 5). The classified map in Figure $6 \mathrm{c}$ and the confusion matrix in Table 5 show that the confusion between agricultural crops (211) and forest cover types (311-313) is almost completely removed. The classified RFTEXSRTM map is also visually more similar to the hybrid level 2/3 CORINE map in Figure 6e than any other classifier.
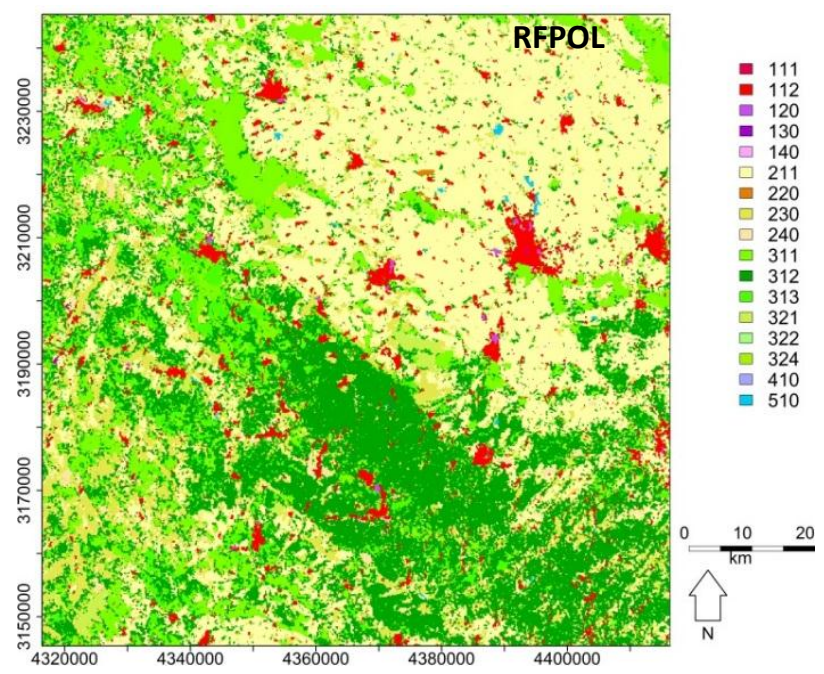

(a)

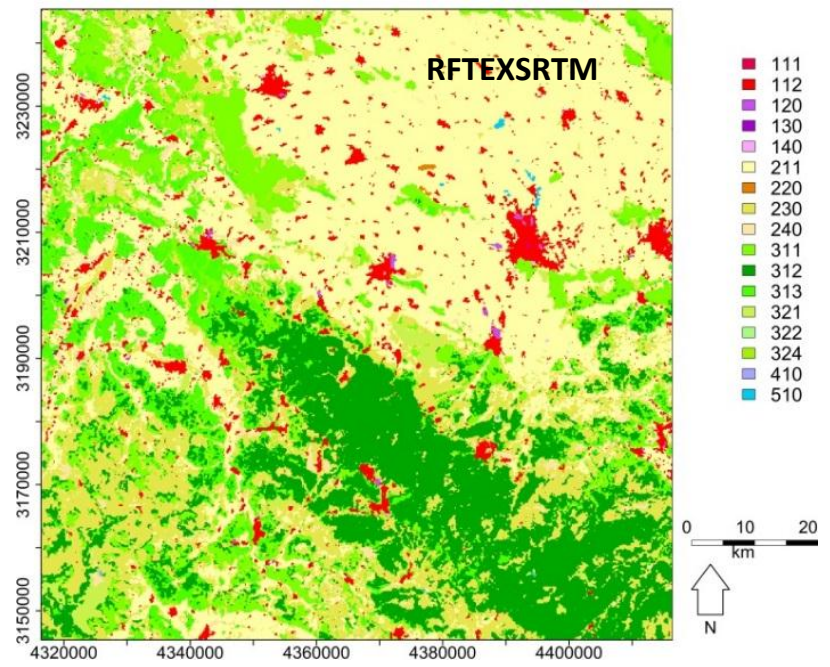

(c)

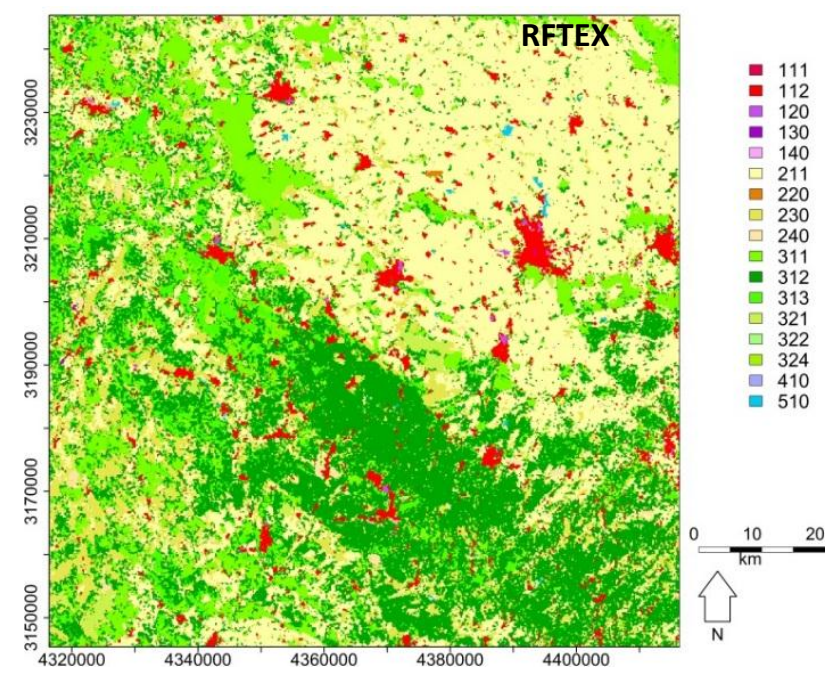

(b)

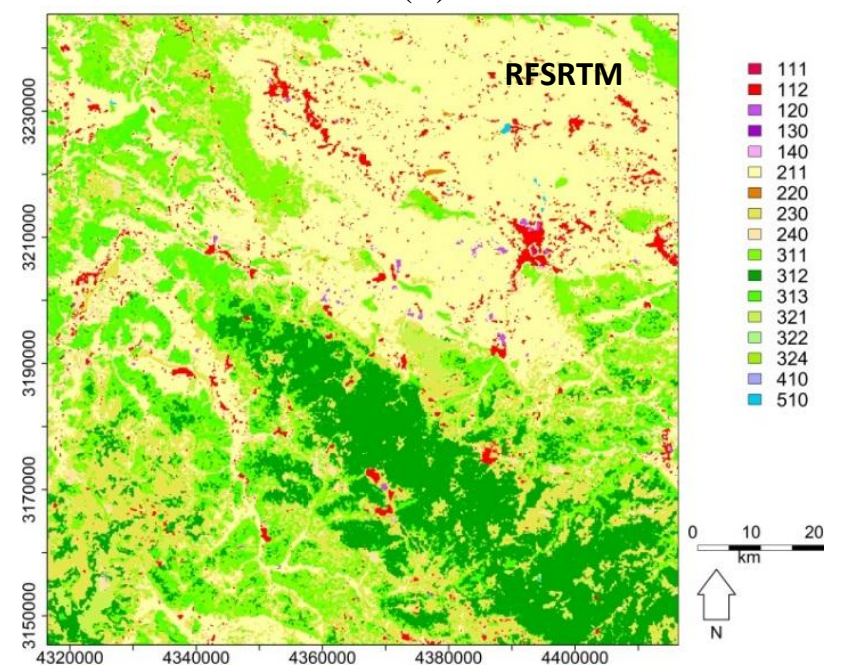

(d)

Figure 6. Cont. 


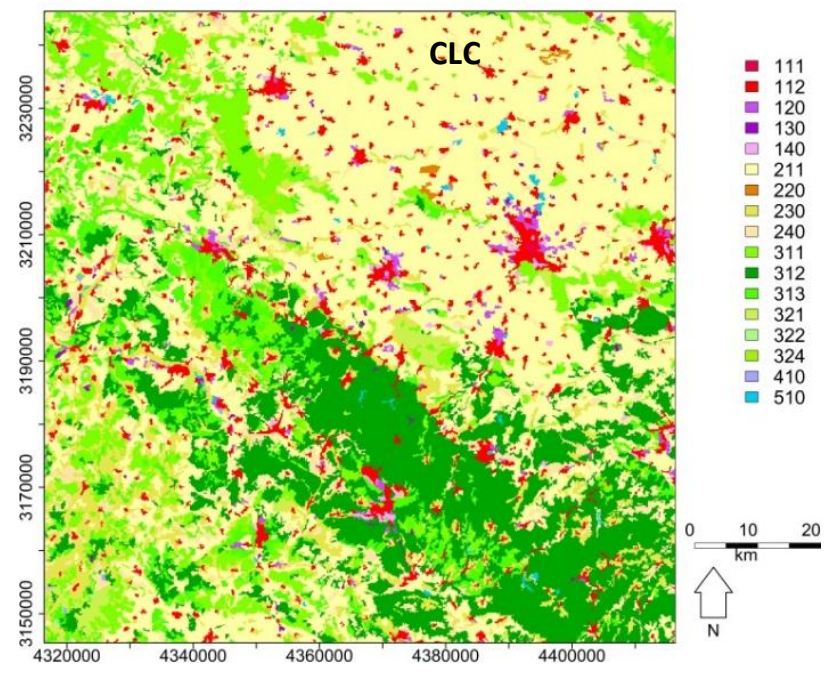

(e)

Figure 6. Classification results according to the hybrid CORINE level $2 / 3$ scheme. (a) RFPOL radiometric classification. (b) RFTEX classification with added HH texture band. (c) RFTEXSRTM classification with HH texture band and SRTM DTM, CHM, SLOPE and ASPECT bands. (d) RFSRTM classification with only the SRTM bands. (e) Original CORINE land cover map (CLC) 2006 with hybrid level 2/3 classes.

We also tested the classification of the SRTM-derived geomorphometric data alone (DTM, CHM, SLOPE and ASPECT) without any Sentinel-1A data to examine whether the terrain shape alone is a sufficient predictor of the CORINE land cover classes in the test area and found that the out-of-bag error rate was $44.3 \%(\kappa=0.48$, Table 6$)$. This is more accurate than using only the Sentinel-1 radiometric bands without terrain information in the RFPOL model but less accurate than combining them in the RFTEXSRTM model.

The results show that the synergies between the information content of the geomorphometric landscape structure from the SRTM derived data bands and the Sentinel-1A radiometry allow a more accurate classification of the CORINE land cover types.

\subsection{Diagnostic Analysis of the RFTEXSRTM Classifier}

To analyse the characteristics of the random forest in more detail, some important properties of the RFTEXSRTM classifier are described in this section. In Figure 7a, the out-of-bag error rate of the random forest classification is decreasing for all classes but the rate of this decrease is slowing as more trees are added. The 201 decision trees that were used in this study are considered sufficient to ensure a stable error rate. Even around 100 trees would achieve similar error rates. The number of nodes of the individual decision trees was between 23,800 and 24,800 nodes with a mean number of 24,278 nodes.

A remaining question is the variable importance of the input bands to the random forest classification. The boxplots in Figures 2 and 3 suggest that the landscape terrain and the canopy height from the SRTM data provide a better class separation than the radiometric bands from the SAR and even the texture bands. 
Table 3. Out-of-bag confusion matrix of the RFPOL classification and the CLC 2006 map. Overall error rate $=52.5 \%$, accuracy $=47.5 \%$, $\kappa=0.38$.

\begin{tabular}{|c|c|c|c|c|c|c|c|c|c|c|c|c|c|c|c|c|c|c|}
\hline Class & 111 & 112 & 120 & 130 & 140 & 211 & 220 & 230 & 240 & 311 & 312 & 313 & 321 & 322 & 324 & 410 & 510 & Class.Error \\
\hline 111 & 15 & 99 & 0 & 0 & 0 & 1 & 0 & 1 & 0 & 3 & 0 & 0 & 0 & 0 & 0 & 0 & 0 & $87 \%$ \\
\hline 112 & 14 & 5161 & 41 & 0 & 1 & 717 & 0 & 292 & 77 & 1244 & 843 & 418 & 19 & 0 & 1 & 0 & 4 & $42 \%$ \\
\hline 120 & 1 & 633 & 37 & 0 & 0 & 185 & 0 & 73 & 17 & 74 & 86 & 22 & 6 & 0 & 0 & 0 & 9 & $97 \%$ \\
\hline 130 & 0 & 3 & 0 & 13 & 0 & 13 & 0 & 13 & 1 & 8 & 9 & 7 & 1 & 0 & 0 & 0 & 0 & $81 \%$ \\
\hline 140 & 0 & 67 & 1 & 0 & 5 & 47 & 0 & 15 & 3 & 47 & 64 & 20 & 1 & 0 & 0 & 0 & 1 & $98 \%$ \\
\hline 211 & 0 & 410 & 23 & 1 & 1 & 14,111 & 3 & 2189 & 243 & 572 & 1796 & 229 & 396 & 0 & 0 & 0 & 26 & $29 \%$ \\
\hline 220 & 0 & 6 & 0 & 0 & 0 & 191 & 2 & 76 & 9 & 4 & 95 & 4 & 8 & 0 & 0 & 0 & 0 & $99 \%$ \\
\hline 230 & 0 & 385 & 16 & 0 & 0 & 3033 & 1 & 6060 & 385 & 905 & 2892 & 472 & 810 & 0 & 0 & 0 & 13 & $60 \%$ \\
\hline 240 & 0 & 273 & 9 & 0 & 1 & 1704 & 5 & 1625 & 169 & 676 & 1544 & 328 & 211 & 0 & 0 & 0 & 4 & $97 \%$ \\
\hline 311 & 0 & 624 & 1 & 0 & 0 & 625 & 3 & 777 & 147 & 12,333 & 2969 & 2421 & 96 & 0 & 1 & 0 & 3 & $38 \%$ \\
\hline 312 & 1 & 523 & 5 & 0 & 0 & 1145 & 4 & 1942 & 273 & 2222 & 11,399 & 2266 & 215 & 0 & 0 & 0 & 5 & $43 \%$ \\
\hline 313 & 0 & 363 & 3 & 1 & 1 & 466 & 0 & 671 & 132 & 4442 & 4498 & 2819 & 76 & 0 & 0 & 0 & 1 & $79 \%$ \\
\hline 321 & 0 & 17 & 1 & 0 & 0 & 910 & 2 & 2031 & 92 & 223 & 1061 & 143 & 664 & 0 & 0 & 0 & 1 & $87 \%$ \\
\hline 322 & 0 & 0 & 0 & 0 & 0 & 1 & 0 & 1 & 0 & 3 & 5 & 1 & 1 & 0 & 0 & 0 & 0 & $100 \%$ \\
\hline 324 & 0 & 3 & 0 & 0 & 0 & 4 & 0 & 4 & 0 & 56 & 35 & 30 & 0 & 0 & 0 & 0 & 0 & $100 \%$ \\
\hline 410 & 0 & 3 & 0 & 0 & 0 & 1 & 0 & 1 & 0 & 9 & 10 & 3 & 1 & 0 & 0 & 0 & 4 & $100 \%$ \\
\hline 510 & 0 & 1 & 8 & 0 & 0 & 100 & 0 & 30 & 2 & 5 & 10 & 3 & 13 & 0 & 0 & 1 & 161 & $52 \%$ \\
\hline
\end{tabular}

Table 4. Out-of-bag confusion matrix of the RFTEX classification and the CLC 2006 map. Overall error rate $=52.5 \%$, accuracy $=47.5 \%$, $\kappa=0.38$.

\begin{tabular}{|c|c|c|c|c|c|c|c|c|c|c|c|c|c|c|c|c|c|c|}
\hline Class & 111 & 112 & 120 & 130 & 140 & 211 & 220 & 230 & 240 & 311 & 312 & 313 & 321 & 322 & 324 & 410 & 510 & Class.Error \\
\hline 111 & 15 & 99 & 0 & 0 & 0 & 1 & 0 & 1 & 0 & 3 & 0 & 0 & 0 & 0 & 0 & 0 & 0 & $87 \%$ \\
\hline 112 & 13 & 5173 & 36 & 0 & 1 & 712 & 1 & 273 & 68 & 1261 & 832 & 433 & 22 & 0 & 2 & 0 & 5 & $41 \%$ \\
\hline 120 & 0 & 645 & 31 & 0 & 0 & 194 & 0 & 65 & 12 & 72 & 81 & 31 & 5 & 0 & 0 & 0 & 7 & $97 \%$ \\
\hline 130 & 0 & 3 & 0 & 12 & 0 & 16 & 0 & 10 & 2 & 10 & 9 & 5 & 1 & 0 & 0 & 0 & 0 & $82 \%$ \\
\hline 140 & 0 & 65 & 0 & 0 & 5 & 46 & 0 & 16 & 5 & 57 & 61 & 12 & 2 & 0 & 0 & 0 & 2 & $98 \%$ \\
\hline 211 & 0 & 401 & 22 & 2 & 1 & 14,133 & 2 & 2204 & 256 & 602 & 1739 & 235 & 377 & 0 & 0 & 0 & 26 & $29 \%$ \\
\hline 220 & 0 & 6 & 0 & 0 & 0 & 194 & 0 & 80 & 6 & 6 & 85 & 7 & 11 & 0 & 0 & 0 & 0 & $100 \%$ \\
\hline 230 & 0 & 393 & 16 & 0 & 0 & 3030 & 3 & 6074 & 377 & 931 & 2871 & 472 & 792 & 0 & 0 & 0 & 13 & $59 \%$ \\
\hline 240 & 0 & 288 & 11 & 0 & 1 & 1680 & 3 & 1650 & 158 & 655 & 1528 & 344 & 226 & 0 & 0 & 0 & 5 & $98 \%$ \\
\hline 311 & 0 & 631 & 4 & 0 & 0 & 626 & 1 & 803 & 133 & 12,368 & 2951 & 2398 & 82 & 0 & 1 & 0 & 2 & $38 \%$ \\
\hline 312 & 1 & 529 & 5 & 0 & 1 & 1126 & 2 & 1971 & 258 & 2254 & 11,333 & 2295 & 218 & 0 & 0 & 0 & 7 & $43 \%$ \\
\hline 313 & 0 & 347 & 3 & 1 & 1 & 490 & 1 & 696 & 112 & 4496 & 4428 & 2833 & 62 & 0 & 0 & 0 & 3 & $79 \%$ \\
\hline 321 & 0 & 22 & 1 & 0 & 0 & 904 & 1 & 2031 & 108 & 209 & 1058 & 139 & 669 & 0 & 0 & 0 & 3 & $87 \%$ \\
\hline 322 & 0 & 0 & 0 & 0 & 0 & 1 & 0 & 1 & 1 & 1 & 7 & 0 & 1 & 0 & 0 & 0 & 0 & $100 \%$ \\
\hline 324 & 0 & 3 & 0 & 0 & 0 & 5 & 0 & 2 & 0 & 60 & 36 & 26 & 0 & 0 & 0 & 0 & 0 & $100 \%$ \\
\hline 410 & 0 & 4 & 0 & 0 & 0 & 1 & 0 & 2 & 0 & 8 & 9 & 3 & 1 & 0 & 0 & 0 & 4 & $100 \%$ \\
\hline 510 & 0 & 2 & 6 & 0 & 0 & 95 & 0 & 39 & 1 & 3 & 11 & 3 & 8 & 0 & 0 & 1 & 165 & $51 \%$ \\
\hline
\end{tabular}


Table 5. Out-of-bag confusion matrix of the RFTEXSRTM classification and CLC 2006. Overall error rate $=31.6 \%$, accuracy $=68.4 \%, \kappa=0.63$.

\begin{tabular}{|c|c|c|c|c|c|c|c|c|c|c|c|c|c|c|c|c|c|c|}
\hline Class & 111 & 112 & 120 & 130 & 140 & 211 & 220 & 230 & 240 & 311 & 312 & 313 & 321 & 322 & 324 & 410 & 510 & Class.Error \\
\hline 111 & 47 & 70 & 1 & 0 & 0 & 1 & 0 & 0 & 0 & 0 & 0 & 0 & 0 & 0 & 0 & 0 & 0 & $61 \%$ \\
\hline 112 & 15 & 6841 & 21 & 0 & 1 & 1105 & 3 & 276 & 80 & 379 & 51 & 41 & 19 & 0 & 0 & 0 & 0 & $23 \%$ \\
\hline 120 & 1 & 596 & 263 & 0 & 0 & 216 & 0 & 54 & 3 & 5 & 0 & 1 & 4 & 0 & 0 & 0 & 0 & $77 \%$ \\
\hline 130 & 0 & 2 & 0 & 19 & 0 & 14 & 0 & 6 & 1 & 16 & 8 & 2 & 0 & 0 & 0 & 0 & 0 & $72 \%$ \\
\hline 140 & 0 & 77 & 0 & 0 & 27 & 48 & 0 & 35 & 11 & 44 & 17 & 7 & 4 & 0 & 0 & 0 & 1 & $90 \%$ \\
\hline 211 & 0 & 583 & 8 & 0 & 2 & 16,905 & 11 & 1596 & 411 & 173 & 37 & 58 & 206 & 0 & 2 & 0 & 8 & $15 \%$ \\
\hline 220 & 0 & 4 & 0 & 0 & 0 & 182 & 175 & 29 & 2 & 0 & 0 & 0 & 3 & 0 & 0 & 0 & 0 & $56 \%$ \\
\hline 230 & 0 & 273 & 5 & 0 & 4 & 1556 & 10 & 10,918 & 539 & 522 & 500 & 116 & 523 & 1 & 1 & 0 & 4 & $27 \%$ \\
\hline 240 & 0 & 224 & 2 & 0 & 2 & 1209 & 0 & 2284 & 1752 & 507 & 231 & 156 & 181 & 0 & 0 & 1 & 0 & $73 \%$ \\
\hline 311 & 0 & 114 & 0 & 0 & 2 & 135 & 0 & 561 & 145 & 14,287 & 2454 & 2252 & 38 & 0 & 12 & 0 & 0 & $29 \%$ \\
\hline 312 & 0 & 16 & 0 & 1 & 1 & 47 & 0 & 585 & 97 & 1664 & 15,735 & 1757 & 96 & 0 & 0 & 0 & 1 & $21 \%$ \\
\hline 313 & 0 & 42 & 0 & 0 & 0 & 95 & 0 & 387 & 155 & 3686 & 3477 & 5610 & 17 & 0 & 4 & 0 & 0 & $58 \%$ \\
\hline 321 & 0 & 22 & 0 & 0 & 0 & 496 & 0 & 899 & 79 & 79 & 105 & 24 & 3440 & 0 & 0 & 1 & 0 & $33 \%$ \\
\hline 322 & 0 & 0 & 0 & 0 & 0 & 0 & 0 & 2 & 0 & 0 & 7 & 0 & 0 & 3 & 0 & 0 & 0 & $75 \%$ \\
\hline 324 & 0 & 1 & 0 & 0 & 0 & 1 & 0 & 10 & 2 & 74 & 6 & 20 & 4 & 0 & 14 & 0 & 0 & $89 \%$ \\
\hline 410 & 0 & 8 & 0 & 0 & 0 & 10 & 0 & 5 & 0 & 0 & 0 & 0 & 3 & 0 & 0 & 5 & 1 & $84 \%$ \\
\hline 510 & 0 & 2 & 0 & 0 & 0 & 77 & 0 & 7 & 0 & 1 & 1 & 0 & 3 & 0 & 0 & 0 & 243 & $27 \%$ \\
\hline
\end{tabular}

Table 6. Out-of-bag confusion matrix of the RFSRTM classification and CLC 2006. Overall error rate $=44.3 \%$, accuracy $=55.7 \%, \kappa=0.48$.

\begin{tabular}{|c|c|c|c|c|c|c|c|c|c|c|c|c|c|c|c|c|c|c|}
\hline Class & 111 & 112 & 120 & 130 & 140 & 211 & 220 & 230 & 240 & 311 & 312 & 313 & 321 & 322 & 324 & 410 & 510 & Class.Error \\
\hline 111 & 22 & 35 & 2 & 0 & 0 & 59 & 0 & 1 & 0 & 0 & 0 & 0 & 0 & 0 & 0 & 0 & 0 & $82 \%$ \\
\hline 112 & 9 & 3094 & 63 & 0 & 2 & 3947 & 26 & 942 & 262 & 220 & 45 & 30 & 182 & 0 & 1 & 0 & 9 & $65 \%$ \\
\hline 120 & 4 & 147 & 289 & 0 & 0 & 553 & 4 & 93 & 13 & 19 & 0 & 4 & 16 & 0 & 0 & 1 & 0 & $75 \%$ \\
\hline 130 & 0 & 2 & 0 & 13 & 0 & 11 & 0 & 6 & 4 & 22 & 7 & 1 & 2 & 0 & 0 & 0 & 0 & $81 \%$ \\
\hline 140 & 0 & 29 & 0 & 0 & 22 & 96 & 2 & 58 & 15 & 25 & 13 & 7 & 4 & 0 & 0 & 0 & 0 & $92 \%$ \\
\hline 211 & 20 & 1696 & 150 & 0 & 15 & 14,726 & 56 & 1634 & 552 & 616 & 26 & 73 & 414 & 0 & 3 & 2 & 17 & $26 \%$ \\
\hline 220 & 0 & 22 & 3 & 0 & 0 & 153 & 180 & 24 & 4 & 9 & 0 & 0 & 0 & 0 & 0 & 0 & 0 & $54 \%$ \\
\hline 230 & 0 & 423 & 25 & 0 & 2 & 1700 & 26 & 9323 & 831 & 1358 & 439 & 210 & 621 & 1 & 10 & 0 & 3 & $38 \%$ \\
\hline 240 & 0 & 259 & 6 & 0 & 1 & 1021 & 2 & 1652 & 2140 & 876 & 154 & 177 & 255 & 0 & 1 & 5 & 0 & $67 \%$ \\
\hline 311 & 0 & 121 & 4 & 3 & 8 & 517 & 1 & 1803 & 569 & 10,142 & 3425 & 3150 & 249 & 0 & 8 & 0 & 0 & $49 \%$ \\
\hline 312 & 0 & 16 & 0 & 2 & 1 & 29 & 0 & 671 & 125 & 3414 & 13,528 & 2074 & 134 & 1 & 1 & 2 & 2 & $32 \%$ \\
\hline 313 & 0 & 39 & 1 & 0 & 1 & 183 & 1 & 576 & 207 & 3714 & 3315 & 5400 & 33 & 0 & 3 & 0 & 0 & $60 \%$ \\
\hline 321 & 0 & 125 & 7 & 0 & 1 & 771 & 0 & 678 & 172 & 246 & 109 & 30 & 3004 & 0 & 0 & 1 & 1 & $42 \%$ \\
\hline 322 & 0 & 0 & 0 & 0 & 0 & 0 & 0 & 2 & 0 & 0 & 5 & 0 & 0 & 5 & 0 & 0 & 0 & $58 \%$ \\
\hline 324 & 0 & 3 & 0 & 0 & 0 & 9 & 0 & 52 & 6 & 53 & 2 & 3 & 2 & 0 & 2 & 0 & 0 & $98 \%$ \\
\hline 410 & 0 & 6 & 1 & 0 & 0 & 9 & 0 & 1 & 5 & 0 & 1 & 0 & 1 & 0 & 0 & 8 & 0 & $75 \%$ \\
\hline 510 & 0 & 22 & 0 & 0 & 0 & 120 & 1 & 12 & 0 & 0 & 0 & 0 & 7 & 0 & 0 & 0 & 172 & $49 \%$ \\
\hline
\end{tabular}




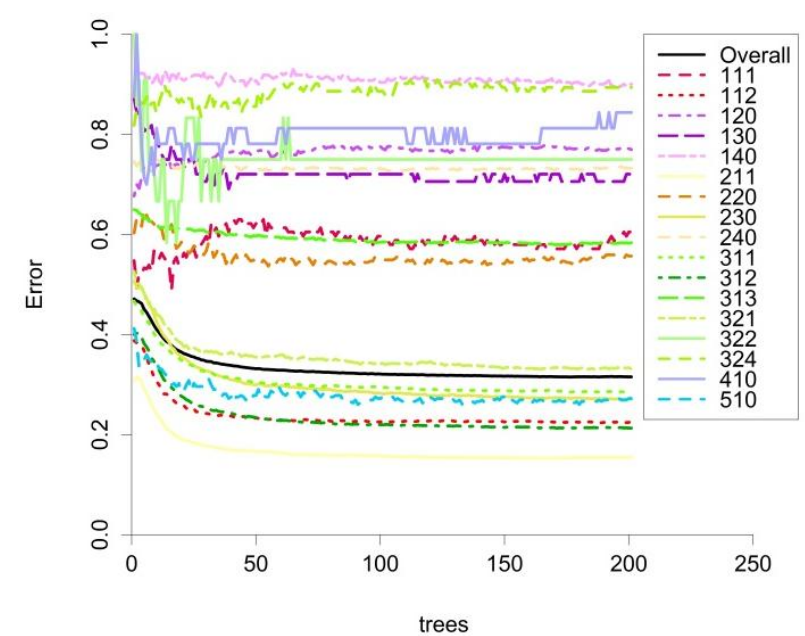

(a)

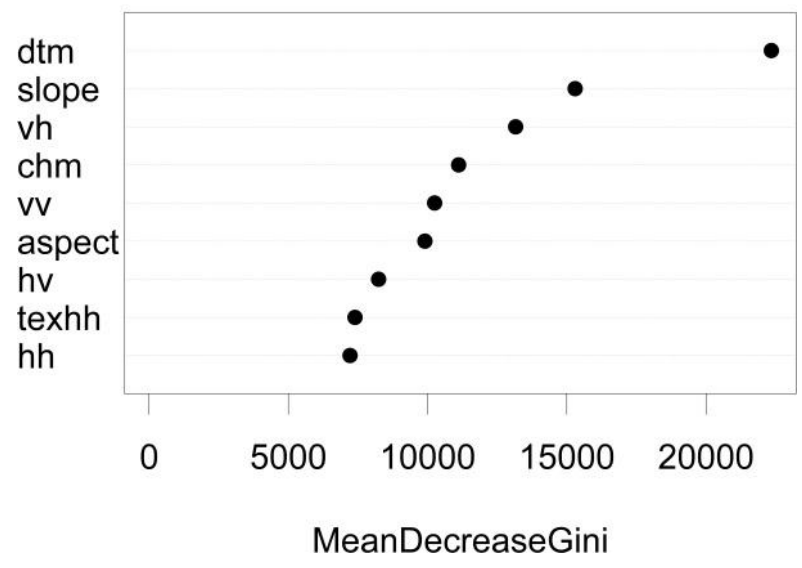

(b)

Figure 7. Diagnostic properties of the RFTEXSRTM Random Forest Classification. (a) Out-of-bag error rate of the Random Forest classification as a function of the number of decision trees used in the algorithm. (b) Decrease of GINI coefficient due to the different input variables, ranked by variable importance.

Figure $7 \mathrm{~b}$ shows that the greatest decrease of the Gini coefficient and consequently the greatest improvement in the class purity was achieved by the DTM input band, followed by SLOPE, VH (December), CHM, VV (December), ASPECT, HV (May), HH texture and HH (May).

\section{Discussion}

The best of the classifiers is the RFTEXSRTM random forest, which uses the SAR backscatter images, HH texture band and SRTM bands as inputs. The out-of-bag error rate of the RFTEXSRTM classifier over the training sites is $31.6 \%$, showing an accuracy of $68.4 \%$ and a $\kappa=0.63$. Given the large number of land cover classes, this is a relatively low error rate considering that some of the non-matching pixels are likely due to the mapping scale differences and to real land cover change between 2006 and 2014.

A visual comparison of the SAR texture band at $\mathrm{HH}$ polarisation in Figure $4 \mathrm{e}$ with the CORINE land cover map in Figure 1a shows that the texture is a good discriminator for urban land cover types while the backscatter intensities highlight vegetated areas very distinctively. Sentinel-1A is a C-band radar and hence the backscatter signal will originate from the top layer of any vegetation canopy. The use of a summer and winter acquisition enables a much better discrimination of agricultural cropland (seasonal vegetation cover) and forests (permanent vegetation cover), which would be confused by a single summer acquisition due to the similarities of volume scattering at C-band in forest and agricultural canopies. Single-date C-band radar backscatter intensity bands cannot distinguish very well between forested areas and dense agricultural crops, hence a radiometric classification of a single image is likely to lead to high rates of classification errors.

The slope map in Figure 5b provides a more robust delineation of areas that are covered by forests than the single-date radiometry from SAR because of the structure of the landscapes in this region 
where steep slopes are often forested. The aspect of a hill side (Figure 5c) can affect land use decisions, since south-facing slopes have higher insolation than north-facing ones.

Figure 6 shows that the Sentinel-1A imagery shows much more spatial detail than the original CORINE map because of the coarse minimum mapping unit of the CORINE land cover map of 25 ha. This characteristic difference in mapping scale makes a direct comparison of the two datasets difficult.

Using too few decision trees in a random forest can deteriorate the classification results. It is therefore important to check how many decision trees are required to achieve a stable error rate of the classification. Generally, the more trees are added, the more accurate the classification. In reality the error rate of the random forest decreases more slowly as more trees are added and approaches a limit when the number of trees is large enough. Here, 201 trees provided a number with stable error rates (Figure 7a).

The findings of this study show that geomorphometric information on the landscape structure can improve classification accuracy when used in a random forest classification approach. While terrain shape alone cannot discriminate between CORINE land cover types, it can help the random forest classifier to distinguish between agricultural crops and forest cover classes that would otherwise appear very similar in a purely radiometric classification.

\section{Conclusions}

Several random forest classifications with different combinations of input bands are compared. Post-classification mode filtering was applied to improve the classified maps. The results show that the random forest with all Sentinel-1A SAR intensity bands from May and December, the HH texture band and four SRTM-derived terrain bands (DTM, CHM, SLOPE and ASPECT) gives the highest classification accuracy (68.4\%) based on the out-of-bag error rates over the randomly selected CORINE 2006 training sites. The classification approach presented here uses the largest number of land cover classes derived from SAR imagery to date, compared to a thorough review of the literature. 27 classes were defined based on a hybrid level 2/3 CORINE nomenclature, of which 17 were found in the study area. In comparison to other types of landscapes in the CORINE mapped area, such as the heterogeneous landscapes of the UK, the study area is relatively simplistic and provides a good test site. The information content in the geomorphometric data layers is highly dependent on the landscape type studied. The applicability to more complex classes will need to be demonstrated in the future.

In its operational phase, Sentinel-1 Interferometric Wide-Swath Mode data will be the default acquisition mode over land areas. Sentinel-1 will thus provide interferometric digital surface models that could in principle allow the derivation of a DTM, CHM, slope and aspect maps to update the SRTM data. However, even with a 6 day temporal baseline, the temporal decorrelation will hinder the generation of DTMs using C-band. Only a passive Sentinel-1 chaser satellite to acquire bistatic interferometric data can alleviate the temporal decorrelation problem. The achievable accuracy of an elevation dataset from Sentinel-1 would be improved significantly if ESA launched a Sentinel-1 Convoy mission with a receive-only SAR sensor, operating in tandem with Sentinel-1A or 1B as a bistatic SAR.

In conclusion, this study shows that Sentinel-1 is an important data source that can complement land cover mapping, especially under cloudy conditions. Random forests and other machine learning 
approaches achieve high classification accuracy when used in conjunction with geomorphometric data from a DTM and CHM and prior information on past land cover.

Under such circumstances, an operational SAR-based land cover monitoring service for a rapid mapping of CORINE land cover change is conceivable if the transferability of the method can be demonstrated. Furthermore, the hyper-temporal coverage of Sentinel-1A (and 1B) will allow the computation of multi-temporal metrics. These metrics have the potential to further improve the delineation of CORINE relevant classes as demonstrated in previous studies $[12,16]$. This will provide the focus of future research.

\section{Acknowledgments}

Heiko Balzter was supported by the Royal Society Wolfson Research Merit Award, 2011/R3 and the NERC National Centre for Earth Observation. The research was underpinned by the GIO-Land project for the UK, which was co-funded by the European Environment Agency (EEA) with financial support from the European Union, and the UK Department for Environment, Food and Rural Affairs (DEFRA). Sentinel-1 data were provided by ESA. CORINE 2006 data were obtained from EEA.

\section{Author Contributions}

Heiko Balzter wrote the R code to analyse the data and wrote the first draft. All authors contributed to the interpretation of the results.

\section{Conflicts of Interest}

The authors declare no conflict of interest.

\section{References}

1. Feranec, J.; Jaffrain, G.; Soukup, T.; Hazeu, G. Determining changes and flows in European landscapes 1990-2000 using CORINE land cover data. Appl. Geogr. 2010, 30, 19-35.

2. Kallimanis, A.S.; Koutsias, N. Geographical patterns of Corine land cover diversity across Europe: The effect of grain size and thematic resolution. Prog. Phys. Geogr. 2013, 37, 161-177.

3. Van der Sande, C.; De Jong, S.; De Roo, A. A segmentation and classification approach of IKONOS-2 imagery for land cover mapping to assist flood risk and flood damage assessment. Int. J. Appl. Earth Obs. Geoinf. 2003, 4, 217-229.

4. Koellner, T.; Scholz, R.W. Assessment of land use impacts on the natural environment. Int. J. Life Cycle Assessment 2008, 13, 32-48.

5. Koellner, T.; de Baan, L.; Beck, T.; Brandão, M.; Civit, B.; Goedkoop, M.; Margni, M.; i Canals, L.M.; Müller-Wenk, R.; Weidema, B.; et al. Principles for life cycle inventories of land use on a global scale. Int. J. Life Cycle Assessment 2013, 18, 1203-1215.

6. Falcucci, A.; Maiorano, L.; Boitani, L. Changes in land-use/land-cover patterns in Italy and their implications for biodiversity conservation. Landsc. Ecol. 2007, 22, 617-631.

7. Gallego, F.J.; Batista, F.; Rocha, C.; Mubareka, S. Disaggregating population density of the European Union with CORINE land cover. Int. J. Geogr. Inf. Sci. 2011, 25, 2051-2069. 
8. Genovese, G.; Vignolles, C.; Nègre, T.; Passera, G. A methodology for a combined use of normalised difference vegetation index and CORINE land cover data for crop yield monitoring and forecasting. A case study on Spain. Agronomie 2001, 21, 91-111.

9. Stathopoulou, M.; Cartalis, C. Daytime urban heat islands from Landsat ETM+ and CORINE land cover data: An application to major cities in Greece. Sol. Energy 2007, 81, 358-368.

10. Büttner, G.; Kosztra, B. CLC2006 Technical Guidelines; European Environment Agency: Copenhagen, Denmark, 2007.

11. Torres, R.; Snoeij, P.; Geudtner, D.; Bibby, D.; Davidson, M.; Attema, E.; Potin, P.; Rommen, B.; Floury, N.; Brown, M.; et al. GMES Sentinel-1 mission. Remote Sens. Environ. 2012, 120, 9-24.

12. Schmullius, C.; Thiel, C.; Pathe, C.; Santoro, M. Radar time series for land cover and forest mapping. In Remote Sensing Time Series; Kuenzer, C., Dech, S., Wagner, W., Eds.; Remote Sensing and Digital Image Processing; Springer International Publishing: Basel, Switzerland, 2015; pp. 323-356.

13. Kwarteng, A.Y.; Dobson, M.C.; Kellndorfer, J.; Williams, R. SAR-based land cover classification of Kuwait. Int. J. Remote Sens. 2008, 29, 6739-6778.

14. Mishra, P.; Singh, D. A statistical-measure-based adaptive land cover classification algorithm by efficient utilization of polarimetric SAR observables. IEEE Trans. Geosci. Remote Sens. 2014, 52 , 2889-2900.

15. Wagner, W.; Sabel, D.; Doubkova, M.; Hornacek, M.; Schlaffer, S.; Bartsch, A. Prospects of Sentinel-1 for land applications. In Proceedings of the 2012 IEEE International Geoscience and Remote Sensing Symposium (IGARSS), Munich, Germany, 22-27 July 2012; pp. 1741-1744.

16. Thiel, C.; Cartus, O.; Eckardt, R.; Richter, N.; Thiel, C.; Schmullius, C. Analysis of multitemporal land observation at C-band. In Proceedings of the 2009 IEEE International Geoscience and Remote Sensing Symposium (IGARSS), Cape Town, South Africa, 12-17 July 2009; doi:10.1109/IGARSS.2009.5417764.

17. Millin-Chalabi, G.; McMorrow, J.; Agnew, C. Detecting a moorland wildfire scar in the Peak District, UK, using synthetic aperture radar from ERS-2 and Envisat ASAR. Int. J. Remote Sens. 2014, 35, 54-69.

18. Park, N.-W.; Chi, K.-H. Integration of multitemporal/polarization C-band SAR data sets for land-cover classification. Int. J. Remote Sens. 2008, 29, 4667-4688.

19. Balzter, H. Forest mapping and monitoring with interferometric synthetic aperture radar (InSAR). Prog. Phys. Geogr. 2001, 25, 159-177.

20. Gaveau, D.L.A.; Balzter, H.; Plummer, S. Forest woody biomass classification with satellite-based radar coherence over $900000 \mathrm{~km}^{2}$ in Central Siberia. For. Ecol. Manag. 2003, 174, 65-75.

21. Li, G.; Lu, D.; Moran, E.; Dutra, L.; Batistella, M. A comparative analysis of ALOS PALSAR L-band and RADARSAT-2 C-band data for land-cover classification in a tropical moist region. ISPRS J. Photogramm. Remote Sens. 2012, 70, 26-38.

22. Longepe, N.; Rakwatin, P.; Isoguchi, O.; Shimada, M.; Uryu, Y.; Yulianto, K. Assessment of ALOS PALSAR $50 \mathrm{~m}$ Orthorectified FBD data for regional land cover classification by Support Vector Machines. IEEE Trans. Geosci. Remote Sens. 2011, 49, 2135-2150. 
23. Esch, T.; Schenk, A.; Ullmann, T.; Thiel, M.; Roth, A.; Dech, S. Characterization of land cover types in TerraSAR-X images by combined analysis of speckle statistics and intensity information. IEEE Trans. Geosci. Remote Sens. 2011, 49, 1911-1925.

24. Riedel, T.; Thiel, C.; Schmullius, C. Fusion of multispectral optical and SAR images towards operational land cover mapping in Central Europe. In Object-Based Image Analysis; Blaschke, T., Lang, S., Hay, G.J., Eds.; Lecture Notes in Geoinformation and Cartography; Springer International Publishing: Berlin, Germany, 2008; pp. 493-512.

25. Satalino, G.; Panciera, R.; Balenzano, A.; Mattia, F.; Walker, J. COSMO-SkyMed multi-temporal data for landcover classification and soil moisture retrieval over an agricultural site in Southern Australia. In Proceedings of the 2012 IEEE International Geoscience and Remote Sensing Symposium (IGARSS), Munich, Germany, 22-27 July 2012; pp. 5701-5704.

26. Cable, J.W.; Kovacs, J.M.; Shang, J.; Jiao, X. Multi-temporal polarimetric RADARSAT-2 for land cover monitoring in northeastern Ontario, Canada. Remote Sens. 2014, 6, 2372-2392.

27. Niu, X.; Ban, Y. Multi-temporal RADARSAT-2 polarimetric SAR data for urban land-cover classification using an object-based support vector machine and a rule-based approach. Int. J. Remote Sens. 2013, 34, 1-26.

28. Evans, T.L.; Costa, M.; Telmer, K.; Silva, T.S.F. Using ALOS/PALSAR and RADARSAT-2 to map land cover and seasonal inundation in the Brazilian Pantanal. IEEE J. Sel. Top. Appl. Earth Obs. Remote Sens. 2010, 3, 560-575.

29. Dobson, M.C.; Pierce, L.E.; Ulaby, F.T. Knowledge-based land-cover classification using ERS-1/JERS-1 SAR composites. IEEE Trans. Geosci. Remote Sens. 1996, 34, 83-99.

30. Niu, X.; Ban, Y. Multitemporal polarimetric RADARSAT-2 SAR data for urban land cover mapping through a dictionary-based and a rule-based model selection in a contextual SEM algorithm. Can. J. Remote Sens. 2013, 39, 138-151.

31. Ullmann, T.; Schmitt, A.; Roth, A.; Duffe, J.; Dech, S.; Hubberten, H.-W.; Baumhauer, R. Land cover characterization and classification of arctic tundra environments by means of polarized synthetic aperture X-and C-Band Radar (PolSAR) and Landsat 8 multispectral imagery-Richards Island, Canada. Remote Sens. 2014, 6, 8565-8593.

32. Breiman, L. Random forests. Mach. Learn. 2001, 45, 5-32.

33. Waske, B.; Braun, M. Classifier ensembles for land cover mapping using multitemporal SAR imagery. ISPRS J. Photogramm. Remote Sens. 2009, 64, 450-457.

34. Van Beijma, S.; Comber, A.; Lamb, A. Random forest classification of salt marsh vegetation habitats using quad-polarimetric airborne SAR, elevation and optical RS data. Remote Sens. Environ. 2014, 149, 118-129.

35. Farr, T.G.; Kobrick, M. Shuttle radar topography mission produces a wealth of data. Eos Trans. Am. Geophys. Union 2000, 81, 583-585.

36. Farr, T.G.; Rosen, P.A.; Caro, E.; Crippen, R.; Duren, R.; Hensley, S.; Kobrick, M.; Paller, M.; Rodriguez, E.; Roth, L.; et al. The shuttle radar topography mission. Rev. Geophys. 2007, doi:10.1029/2005RG000183.

37. Kobrick, M. On the toes of giants-How SRTM was born. Photogramm. Eng. Remote Sens. 2006, $72,206-210$. 
38. Hensley, S.; Rosen, P.; Gurrola, E. Topographic map generation from the shuttle radar topography mission C-band SCANSAR interferometry. Proc. SPIE 2000, 4152, 179-189.

39. R Core Team. R: A Language and Environment for Statistical Computing; R Foundation for Statistical Computing: Vienna, Austria, 2014.

40. Liaw, A.; Wiener, M. Classification and Regression by randomForest. R News 2002, 2, 18-22.

41. Pebesma, E.J.; Bivand, R.S. Classes and methods for spatial data in R. R News 2005, 5, 9-13.

42. Bivand, R.S.; Pebesma, E.; Gomez-Rubio, V. Applied Spatial Data Analysis with R, 2nd ed.; Springer: New York, NY, USA, 2013.

(C) 2015 by the authors; licensee MDPI, Basel, Switzerland. This article is an open access article distributed under the terms and conditions of the Creative Commons Attribution license (http://creativecommons.org/licenses/by/4.0/). 